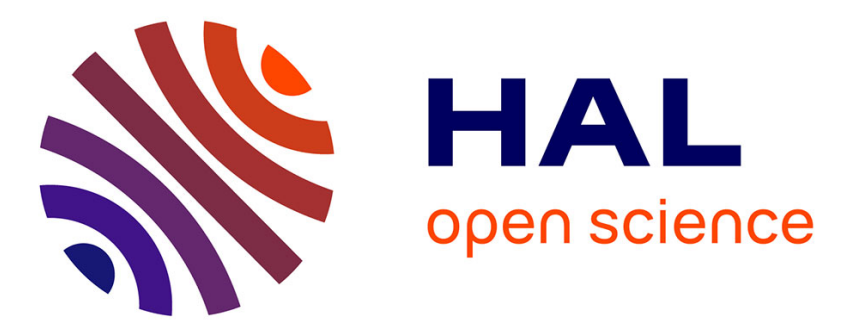

\title{
High-density lipoprotein phospholipids interfere with dendritic cell Th1 functional maturation
}

Laure Perrin-Cocon, Olivier Diaz, Martine Carreras, Sandra Dollet, Aurélie Guironnet-Paquet, Patrice André, Vincent Lotteau

\section{To cite this version:}

Laure Perrin-Cocon, Olivier Diaz, Martine Carreras, Sandra Dollet, Aurélie Guironnet-Paquet, et al. High-density lipoprotein phospholipids interfere with dendritic cell Th1 functional maturation. Immunobiology, 2011, 217 (1), pp.91-99. 10.1016/j.imbio.2011.07.030 . inserm-02443454

HAL Id: inserm-02443454 https://www.hal.inserm.fr/inserm-02443454

Submitted on 17 Jan 2020

HAL is a multi-disciplinary open access archive for the deposit and dissemination of scientific research documents, whether they are published or not. The documents may come from teaching and research institutions in France or abroad, or from public or private research centers.
L'archive ouverte pluridisciplinaire HAL, est destinée au dépôt et à la diffusion de documents scientifiques de niveau recherche, publiés ou non, émanant des établissements d'enseignement et de recherche français ou étrangers, des laboratoires publics ou privés. 


\title{
High-density lipoprotein phospholipids interfere with dendritic cell Th1
}

\section{functional maturation}

\author{
Laure Perrin-Cocon $^{\mathrm{a}, \mathrm{b}, *}$, Olivier Diaz ${ }^{\mathrm{a}, \mathrm{b}}$, Martine Carreras $^{\mathrm{a}, \mathrm{b}}$, Sandra Dollet ${ }^{\mathrm{a}, \mathrm{b}}$, Aurélie \\ Guironnet-Paquet $^{\mathrm{a}, \mathrm{b}, \mathrm{c}}$, Patrice André ${ }^{\mathrm{a}, \mathrm{b}, \mathrm{c}}$ and Vincent Lotteau ${ }^{\mathrm{a}, \mathrm{b}, \mathrm{c}}$ \\ ${ }^{a}$ Université de Lyon, France \\ b INSERM, U851, 21 Avenue Tony Garnier, Lyon, F-69365, France \\ ${ }^{\mathrm{c}}$ Hospices civils de Lyon, Hôpital de la Croix Rousse, Laboratoire de Virologie, France
}

* Correspondence: Dr. L. Perrin-Cocon, INSERM U851, 21 Avenue Tony Garnier, 69365 Lyon

Cedex 7, France. E-mail: laure.perrin@inserm.fr

Tel: (+33)-437282447; Fax: (+33)-437282341

Short title: HDL interfere with dendritic cell maturation

Key words: atherosclerosis; dendritic cell function; immunomodulation; lipoprotein; Th1 response.

Abbreviations: VLDL, very low density lipoprotein; IDL, intermediate density lipoprotein; LDL, low density lipoprotein; HDL, high density lipoprotein; oxLDL, oxidized LDL; Apo, apolipoprotein; DC, dendritic cells; IL, interleukin; IFN, interferon; TLR, toll-like receptor; LPS, lipopolysaccharide; PGN, peptidoglycan; pIC, poly(I)/poly(C); Pam, Pam3CSK4; MLR, mixed leukocyte reaction; LPDS, lipoprotein-deficient foetal calf serum; PL, phospholipid; TG, triglyceride; CE, cholesteryl ester; PC, phosphatidylcholine; PLPC, 1-palmitoyl-2-linoleyl-phosphatidylcholine; POPC, 1- palmitoyl-2oleoyl-phosphatidyl-choline; SLPC, 1-stearoyl-2-linoleyl-phosphatidylcholine; PAPC, 1-palmitoyl-2arachidonoyl-phosphatidylcholine; PPPC, dipalmitoyl-phosphatidylcholine; LPC, lysophosphatidylcholine; LA, linoleic acid; HODE, hydroxy-octadecadienoic acid; PPAR, peroxisome proliferator-activated receptor; EMSA, electrophoretic mobility shift assay. 


\begin{abstract}
Lipoproteins are both lipid carriers in the blood and regulators of essential biological processes. Several studies demonstrated that lipoproteins modified during pathological conditions could alter dendritic cell (DC) maturation. Here the immune function of non-pathological lipoproteins is addressed by analysing their impact on human DC maturation triggered by TLR ligands. Upon TLR4 stimulation, low- and high-density lipoproteins (LDL and HDL) strongly inhibited the ability of DC to induce a Th1 response of T cells, characterized by high levels of IFN $\gamma$ secretion, whereas the effect of very low-density lipoprotein was subject to variations. HDL also inhibited the Th1 function of DC stimulated by TLR1/2 and TLR2/6 ligands. The phospholipid fraction from HDL retained the inhibitory activity of the lipoprotein. We identified the 1-palmitoyl-2-linoleyl-phosphatidylcholine (PLPC) as one active phospholipid that inhibited the Th1 function of mature DCs whereas the dipalmitoyl-phosphatidylcholine had no significant effect. The treatment of DC by PLPC, $24 \mathrm{~h}$ before TLR4 stimulation, resulted in reduced activation of NF- $\kappa B$. This study shows that some HDL phospholipids have a direct immunoregulatory function, by modulating DC ability to activate a Th1 response of $\mathrm{T}$ cells.
\end{abstract}




\section{Introduction}

Lipoproteins are essential lipid carriers in the blood that are secreted by the liver and the intestine. Chylomicrons secreted by enterocytes after fat diet absorption, transport lipids from the gut to the liver. After rearrangement of endogenous and exogenous lipids, hepatocytes secrete very low density lipoproteins (VLDL). Transformation of VLDL in the circulation gives rise to particles of smaller size, with intermediate to low density (intermediate-density lipoprotein (IDL) and low-density lipoprotein (LDL)). High-density lipoprotein (HDL) synthesis requires the secretion of apolipoprotein (Apo) A-I by intestine and liver cells and the gradual extracellular lipidation of nascent HDL by lipid transfer (mainly phospholipids and cholesterol) from the peripheral tissues and other lipoproteins. HDL plays an important role in the reverse cholesterol transport from the peripheral tissues to the liver (Lewis and Rader, 2005).

In addition, lipoproteins are modulators of essential biological processes (Barter, 2005; Navab et al., 2009; Scanu and Edelstein, 2008). HDL especially has crucial atheroprotective properties relying on diverse functions, including anti-inflammatory, anti-thrombotic and anti-oxidant properties. HDL has potent anti-inflammatory properties that have mainly been studied on endothelial cells (Norata et al., 2005). It can neutralize pro-inflammatory activities of the C-reactive protein, inhibiting the expression of adhesion molecules (Wadham et al., 2004) and can reduce monocyte activation triggered by CD11b as well as monocyte adhesion and transmigration (Murphy et al., 2008). HDL also inactivates some pro-inflammatory lipids generated during LDL oxidation, by reaction with ApoA-I or hydrolysis by HDL-associated enzymes such as paraoxonase or platelet-activating factor acetyl hydrolase.

Low levels of HDL are frequently associated not only to inflammatory diseases but also to immune diseases suggesting a role for HDL in immunomodulation (Yu et al., 2010). An increasing number of studies show that lipoproteins can regulate the innate and adaptive immune system. Atherosclerosis is considered as an inflammatory pathology, linked to chronic inflammation of arteries, in which activation of the immune system plays a major role. It is characterized by the accumulation of macrophages, T lymphocytes and oxidized LDL (oxLDL) in the arterial intima. Cells of the immune system and especially dendritic cells (DCs) strongly contribute to atherogenesis (Niessner and Weyand, 2010). DC activation of T cells within the atheroma's plaque plays a critical role in the 
outcome of the disease, by destabilizing the plaque. In atherosclerosis and autoimmune diseases, Th1 cells predominate, leading to excessive release of pro-inflammatory cytokines regulating cellmediated immunity. Indeed, human atherosclerotic lesions are infiltrated by activated DCs and Th1 lymphocytes producing high amount of interferon (IFN) $\gamma$ (Hansson et al., 1989). In ApoE knock-out mice, the reduction of the Th1 immune response (Laurat et al., 2001) or a deficiency in IFN $\gamma$ (Nagano et al., 1997; Raisanen-Sokolowski et al., 1998) reduces atherogenesis whereas the injection of IFN $\gamma$ potentiates atherosclerosis (Gupta et al., 1997).

Modifications of HDL affecting their anti-inflammatory functionality frequently occur during pathological conditions such as diabetes, chronic inflammation linked to Crohn's disease (van Leuven et al., 2007), systemic lupus erythematous and rheumatoid arthritis (McMahon et al., 2006), coronary artery disease or infection (Sviridov et al., 2008) and also during the acute phase response (Jahangiri et al., 2009). Indeed, Serum Amyloid A is synthesized in high amount and can displace and inactivate HDL-associated enzymes that protect LDL from oxidation (Van Lenten et al., 1995). Oxidation, nitration and advanced glycation occurring in diabetes are examples of modifications that decrease the anti-inflammatory properties of HDL (Sviridov et al., 2008).

OxLDL favours the development of atherosclerosis by several ways. It stimulates the secretion of monocyte chemotactic protein-1 by endothelial cells, increasing transmigration of monocytes across the endothelial cell layer to enter the subendothelial space (Navab et al., 1991). In the tissue, monocytes can differentiate into macrophages or DCs depending on environmental conditions (Randolph et al., 1998). Both macrophages and mature DCs secrete pro-inflammatory cytokines that increase the expression of adhesion molecules on endothelial cells, enhancing the recruitment of monocytes (Kume et al., 1992). OxLDLs accumulating in the arterial intima can interfere with both macrophages and DC function. Internalization of oxLDL by macrophages converts them into foam cells that are a hallmark of atherosclerosis. We have also previously discovered that oxLDL promotes mature DC generation in vitro by delivering instructive molecules such as lysophosphatidylcholine (LPC) (Coutant et al., 2002; Coutant et al., 2004; Perrin-Cocon et al., 2001). In vivo, LPC is an immunostimulating molecule, inducing both humoral and cellular immune responses (Perrin-Cocon et 
al., 2006). Our results also indicated that LPC-induced DC maturation is associated with the inhibition of peroxisome proliferator-activated receptor (PPAR) $\gamma$ activity while maintaining PPAR $\gamma$ activation by oxidized fatty acids or synthetic ligands impairs the functional maturation of DCs that lose their ability to stimulate the Th1 function of T cells (Coutant et al., 2004). Native LDL can prevent DC maturation induced by oxLDL or LPC, suggesting that the balance between native and oxidized LDL regulates the activation threshold of DC (Perrin-Cocon et al., 2001). These studies indicate that some biochemical modifications of lipoproteins may reflect an abnormal situation and provide regulatory signals to the immune system. Lipoproteins thus play an active role at the interface between innate and adaptive immunity.

To further investigate the role of lipoproteins in the regulation of DC maturation, we analysed the impact of VLDL, LDL and HDL on TLR-stimulated DCs. Using monocyte-derived DCs, the present work shows that HDL can directly impair the functional maturation of DCs altering their ability to induce a Th1 response upon TLR stimulation and describes the role of different lipid components of HDL in this process. 


\section{Materials and methods}

\section{Materials}

Synthetic lipids were purchased from Avanti Polar Lipids (Alabaster, AL, USA) and solubilized in ethanol at $10 \mathrm{mg} / \mathrm{ml}$. To avoid oxidation during storage, lipoproteins and lipids were kept under nitrogen atmosphere. Ultrapure Escherichia Coli 011:B4 lipopolysaccharide (LPS) was from InvivoGen (San Diego, CA, USA), peptidoglycan (PGN) from Staphylococcus aureus was from Sigma (St Quentin Fallavier, France), Pam3CSK4 (Pam) was from Alexis Biochemical (Lausen, Switzerland), double-stranded poly(I)/poly(C) (pIC) was from GE healthcare (Uppsala, Sweden).

\section{Lipoprotein preparation}

Lipoproteins were isolated by sequential floatation from human plasma of normolipidemic healthy blood donors (Etablissement Français du Sang) (Havel et al., 1955). After ultracentrifugation at 100 $000 \mathrm{rpm}, 4^{\circ} \mathrm{C}$ for $4 \mathrm{~h}$ using a TL 100.4 rotor, the floating fraction containing chylomicron and VLDL was collected. The density of the plasma was raised using $\mathrm{NaBr}$ and after ultracentrifugation in the same conditions, floating IDL was removed (d $\leq 1.025)$. LDL $(1.025 \leq \mathrm{d} \leq 1.055 \mathrm{~g} / \mathrm{ml})$ and HDL $(1.055 \leq \mathrm{d} \leq 1.21 \mathrm{~g} / \mathrm{ml})$ were collected after sequential ultracentrifugation as above. Lipoproteins were dialyzed extensively against $\mathrm{NaCl} 150 \mathrm{mM}$ / EDTA $2.4 \mathrm{mM}$ pH 7.2 at $4^{\circ} \mathrm{C}$, filtered at $0.45 \mu \mathrm{m}$ and stored in the dark under nitrogen. The protein content was estimated by Coomassie Protein MicroAssay procedure (Pierce, Rockford, IL, USA) and lipid composition was determined using Cholesterol RTU, Triglycerides enzymatic PAP 150 and Phospholipids enzymatic PAP 150 assay kits from bioMérieux (Marcy l’Etoile, France).

\section{Lipid extraction and purification}


Lipid extracts were obtained following the Folch procedure (Folch et al., 1957) from $10 \mathrm{ml}$ of lipoprotein fraction. Lipids were separated on Silica Gel G60 plates (Sigma) with the solvent system hexane/diethyl ether/acetic acid (80:20:1, by vol.). The silica-gel areas corresponding to phospholipids (PL), triglycerides (TG) and cholesteryl esters (CE) were scraped off and lipids were extracted twice with $3 \mathrm{ml}$ chloroform/methanol (2:1, by vol.) from the silica-gel and dried under a stream of nitrogen before quantification.

Total lipids and PL extracts were quantified by the lipid phosphate measurement method as previously described (Kates, 1986). Quantification was realized by comparison to a standard curve established with $\mathrm{NaH}_{2} \mathrm{PO}_{4}$ treated in the same conditions. TG and $\mathrm{CE}$ were quantified as above, using enzymatic kits, after lipid resuspension.

\section{Monocytes and $T$ cells separation}

Mononuclear cells were isolated from human peripheral blood by density gradient centrifugation on Ficoll-Hypaque (GE healthcare). Monocytes were separated from dense lymphocytes by centrifugation on a $50 \%$ Percoll solution. Monocytes were further purified by immunomagnetic depletion (Dynal, Oslo, Norway) using a cocktail of monoclonal antibodies anti-CD19 (4G7 hybridoma), anti-CD3 (OKT3, ATCC, Rockville, MD, USA) and anti-CD56 (NKH1, Beckman Coulter, Fullerton, CA, USA). They were more than $90 \%$ pure as assessed by CD14 labelling. T lymphocytes were purified from lymphocytes by immunomagnetic depletion using a cocktail of monoclonal antibodies anti-CD19 (4G7), anti-CD16 (3G8), anti-CD56 (NKH1), anti-glycophorin A (11E4B7.6) and anti-CD14 (RMO52) all from Beckman Coulter. T lymphocytes were more than 95 $\%$ pure as assessed by CD3 labelling.

\section{Monocyte-derived DC differentiation and maturation}

Purified monocytes $\left(10^{6}\right.$ cells $\left./ \mathrm{ml}\right)$ were differentiated to immature DC in complete RPMI 1640 medium supplemented with $2 \mathrm{mM}$ glutamine, $10 \mathrm{mM}$ HEPES, $40 \mathrm{ng} / \mathrm{ml}$ gentamycin, $10 \%$ 
lipoprotein-deficient foetal calf serum (LPDS, Sigma), $50 \mathrm{ng} / \mathrm{ml}$ human Granulocyte MacrophageColony Stimulating Factor and $62.5 \mathrm{ng} / \mathrm{ml}$ human interleukin (IL)-4 (from AbCys, Paris, France) during 6 days. Lipoproteins or lipids, stored under nitrogen atmosphere, were added at day 4. HDL lipids as well as synthetic lipids were dissolved in ethanol and control cells were treated with the same volume of ethanol. Maturation of DC was induced at day 5 with LPS $(1 \mu \mathrm{g} / \mathrm{ml})$, PGN $(10 \mu \mathrm{g} / \mathrm{ml})$, Pam $(10 \mu \mathrm{g} / \mathrm{ml})$ or $\mathrm{pIC}(10 \mu \mathrm{g} / \mathrm{ml})$. All cells and culture supernatants were collected at day 6 .

\section{Cell surface staining}

Phenotype was analysed by flow cytometry on a FACSarray (BD Biosciences, Franklin Lakes, NJ, USA) using FITC-conjugated anti-CD14, -HLA-DR, -CD80, -CD54 and phycoerythrine-conjugated anti-CD1a, -CD86, -CD83 and -CD40 (all from Beckman Coulter).

$M L R$

Primary MLR were conducted in 96-well flat-bottom culture plates, by co-incubation of DC with T cells isolated from a different blood donor. DC collected at day 6, were extensively washed and resuspended in RPMI 1640 supplemented with $2 \mathrm{mM}$ glutamine, $10 \mathrm{mM}$ HEPES, $40 \mathrm{ng} / \mathrm{ml}$ gentamycin and $10 \%$ FCS (BioMedia, Boussens, France). Cells were then co-cultured with $2 \times 10^{5}$ allogeneic T cells in $200 \mu \mathrm{l}$ complete culture medium at 1/10, 1/20 and 1/40 DC/T cells ratios. After 5 days, coculture supernatants were harvested.

Cytokine assay

Culture supernatants were stored at $-80^{\circ} \mathrm{C}$. Cytokine concentrations were determined using sandwich ELISA specific for IL-12 p40 (Invitrogen, Cergy Pontoise, France), IL-6, tumour necrosis factor (TNF) $\alpha$, IL-10 (Endogen, Woburn, MA, USA) or using Cytometric Bead Array flex sets (BD biosciences) for IFN $\gamma$, IL-5 and IL-13. 
Electrophoretic mobility shift assay (EMSA)

After treatment, cells $\left(4 \times 10^{6}\right)$ were harvested and nuclear proteins were extracted. Cells were washed twice with PBS, resuspended in $400 \mu$ l of ice-cold hypotonic buffer (10 mM HEPES (pH 7.9) / 10 $\mathrm{mM} \mathrm{KCl} / 0.01 \mathrm{M}$ DTT / $1.5 \mathrm{mM} \mathrm{MgCl} / 1 \mathrm{X}$ protease inhibitor cocktail (Sigma)), left on ice for 15 min, vortexed and centrifuged at $15,000 \mathrm{~g}$ for $1 \mathrm{~min}$ at $4^{\circ} \mathrm{C}$. Sedimented nuclei were resuspended in $40 \mu \mathrm{l}$ ice-cold saline buffer (20 mM HEPES (pH 7.9) / $420 \mathrm{mM} \mathrm{NaCl} / 0.2 \mathrm{mM}$ EDTA / $1.5 \mathrm{mM}$ $\mathrm{MgCl}_{2} / 25 \%$ glycerol / $1 \mathrm{X}$ protease inhibitor mixture (Sigma)), left on ice for $20 \mathrm{~min}$, vortexed and centrifuged at $15,000 \mathrm{~g}$ for $5 \mathrm{~min}$ at $4^{\circ} \mathrm{C}$. Nuclear protein concentration in the extracts was determined by Coomassie plus Assay (Pierce, Rockford, IL, USA). The binding activity of NF- $\kappa B$ was determined as described (Coutant et al., 2004) using a specific DNA probe: 5'AGTTGAGGGGACTTTCCCAGG-3'. The oligonucleotide was end-labelled with $\left[\gamma_{-}{ }^{32} \mathrm{P}\right] \mathrm{ATP}$ (Perkin Elmer, Waltham, MA, USA) by T4 polynucleotide kinase (New England Biolab, Beverly, MA, USA). For the binding reaction, 0.5 or $1 \mu \mathrm{g}$ of nuclear extract proteins was incubated at room temperature for 20 min with a reaction mixture containing $2 \mu \mathrm{g}$ of poly (dI-dC) (GE healthcare), $4 \mu 1$ of $5 \mathrm{X}$ binding buffer (final concentration: $10 \mathrm{mM}$ Tris (pH 7.5) / $50 \mathrm{mM} \mathrm{NaCl} / 1 \mathrm{mM}$ DTT / $1 \mathrm{mM}$ EDTA / 5\% glycerol), and $50000 \mathrm{cpm}$ of $\left[{ }^{32} \mathrm{P}\right]$-labelled oligonucleotide in a final volume of $20 \mu \mathrm{l}$. To confirm the specificity of the binding reaction, unlabelled competitor oligonucleotide was added in 50-fold excess. DNA-protein complexes were separated from unbound DNA probe by electrophoresis on a $4 \%$ polyacrylamide non denaturing gel in $0.5 \mathrm{X}$ Tris-glycine EDTA buffer. Gels were dried and [ $\left.{ }^{32} \mathrm{P}\right]-$ labelled oligonucleotide was visualized using a Typhoon PhosphorImager. ImageQuant software was used for quantification of band intensities. 


\section{Results}

Lipoproteins do not alter TLR4-induced phenotypic maturation of DC

DCs were differentiated from monocytes in a lipoprotein free culture medium for 6 days and their maturation was induced by addition of TLR ligands for the last $24 \mathrm{~h}$ of culture, as previously described (Agaugue et al., 2007). VLDL, LDL and HDL from healthy donors were isolated according to their density by differential ultracentrifugation. To analyse their impact on DC maturation, lipoproteins were added at day 4 on differentiating DC, $24 \mathrm{~h}$ prior induction of maturation by TLR ligands (Fig. 1A). DCs were collected at day 6 and their phenotype was analysed. As previously shown (Coutant et al., 2002; Coutant et al., 2004; Perrin-Cocon et al., 2001), non-stimulated control DCs displayed the phenotype of immature DCs, with high level of CD1a, low level of HLA-DR, CD54 and CD40 and no expression of the maturation markers CD86, CD80 and CD83. TLR4 stimulation by LPS induced an efficient maturation, strongly increasing the expression of the antigen presentation molecule HLADR, the adhesion molecule CD54 and the T cell stimulation molecule CD40. TLR4 stimulation also induced the expression of costimulation molecules CD86, CD80 and the maturation marker CD83. To compare the impact of the different lipoproteins on DC maturation, VLDL, LDL and HDL were introduced in DC culture at a constant final concentration of PL $(50 \mu \mathrm{g} / \mathrm{ml})$. The corresponding amounts of TG and CE introduced in the culture medium are presented in Table 1. Addition of lipoproteins on DCs did not affect the phenotype of non-stimulated cells (data not shown), nor the phenotype of LPS-stimulated DCs (Fig. 1B). Therefore, the maturation of DCs at the phenotypic level does not seem to be affected by lipoproteins.

LDL and HDL inhibit the Th1-function of TLR4-stimulated DC

LPS-treated DCs have the ability to stimulate T cells, inducing a robust Th1 response characterized by the secretion of high levels of IFN $\gamma$. DCs treated with LDL or HDL prior to maturation, were strongly 
impaired in their ability to activate $\mathrm{T}$ cells (Fig. 1C). The amount of IFN $\gamma$ secreted in coculture supernatants was reduced by $76 \%$ and $87 \%$ for LDL and HDL respectively $(\mathrm{p}<0.05$ and $\mathrm{p}<0.03$ in a pairwise student's test). In mean, a slight inhibition was also observed with VLDL treatment but this was subject to variations depending on the plasma donor. We did not observe any induction of secretion of IL-5 and IL-13 correlated to the decrease in IFN $\gamma$, indicating that there is no Th2 shift of DC function (data not shown).

Cytokines secreted by DCs play an important role in the regulation of $\mathrm{T}$ cell stimulation. Therefore, supernatants of DCs collected at the end of the maturation process were assayed for their content in IL-6, TNF $\alpha$, IL-12 and IL-10. IL-12 is an immunoregulatory cytokine favouring the development of a pro-atherosclerotic Th1 response (Lee et al., 1999). It is produced by various cell types and especially by activated DCs, which are potent activators of naïve T cells. The secretion of high amounts of IL-12 by DCs favours the differentiation of T lymphocytes toward Th1 cells. In $\mathrm{ApoE}^{-/-}$mice under a high cholesterol and fat content diet, dyslipidaemia alters TLR mediated activation of IL-12 secretion by DC and drives a Th2 rather than Th1 immune response (Shamshiev et al., 2007). Our data indicate that only HDL treatment induced a slight decrease of IL-12 secretion by LPS-stimulated DCs (Fig. 1D). All lipoproteins induced a slight reduction of TNF $\alpha$ secretion whereas IL-6 and IL-10 secretion by mature DC was not affected by lipoprotein treatment (data not shown).

Therefore, LDL and HDL interfere with TLR4 signalling, altering the acquisition of functional properties needed for mature DCs to induce a Th1 response. Because HDL has the most significant effect on DC function, we then focused on the exploration of the downregulatory function of this lipoprotein.

$H D L$ interferes with the functional maturation of DC triggered by various TLR stimulations

The effect of HDL on TLR4-stimulation of DC maturation was dependent on the dose of HDL introduced in the culture. Functional impairment of DC could be observed with 20 and $50 \mu \mathrm{g} / \mathrm{ml}$ of HDL (47 and $64 \%$ inhibition, respectively) (Fig. 2A). 
We then analysed the effect of HDL on DC maturation triggered by other TLR pathways. Similarly to TLR4 stimulation, HDL strongly inhibited the ability of DCs to activate IFN $\gamma$ secretion by $\mathrm{T}$ cells upon stimulation by PGN or Pam, the ligands of TLR2/6 and TLR1/2 respectively (Fig. 2B). In mean, HDL pre-treatment of DC reduced by around $50 \%$ the IFN $\gamma$ secretion induced by stimulated DCs (Fig. 2C). Therefore, the inhibitory effect of HDL is not restricted to TLR4 but extends to TLR2/6 and TLR1/2 stimulations.

The phospholipid fraction from HDL inhibits the functional maturation of DC

Using MLR experiments, we then compared the effect of HDL to that of lipids extracted from HDL on the ability of DCs to stimulate T cells. To avoid oxidation during storage, lipoproteins and lipids were kept under nitrogen atmosphere. HDL and the extracted lipids (total lipids) had the same ability to inhibit functional maturation of DCs, resulting in a more than $70 \%$ inhibition of IFN $\gamma$ secretion by T cells (Fig. 3A). The 3 main classes of HDL lipids (PL, TG and CE) were separated by preparative thin layer chromatography. Their effect on DC maturation was analysed, adjusting their concentration to match their equivalent in HDL (cf. Table 1), except for PL that was introduced at $10 \mu \mathrm{g} / \mathrm{ml}$ because of toxicity at $50 \mu \mathrm{g} / \mathrm{ml}$. At this low concentration, PL from HDL could strongly inhibit the functional maturation of DCs induced by LPS (Fig. 3A). CE had a weak but recurrent inhibitory effect on DC function while the effect of TG on DC function was greatly variable. IL-12 secretion by DCs was reduced when cells were treated with HDL, total lipids, PL and TG extracted from HDL prior to LPS stimulation (Fig. 3B). Although reduction of IL-12 secretion could contribute to the decreased ability of DCs to stimulate a Th1 response, a strict correlation between the two events was not observed.

To identify bioactive molecules that could downregulate the Th1 function of mature DCs, we next focused on PL from HDL. A potent inhibition of DC Th1 function was observed with $2.5 \mu \mathrm{g} / \mathrm{ml}$ of PL (Fig. 4A) whereas no significant inhibition could be observed with $1 \mu \mathrm{g} / \mathrm{ml}$ (data not shown).

PLPC is a potent inhibitor of TLR4-induced functional maturation of DC 
In HDL, PL is mainly composed of phosphatidylcholine (PC, around 80\%) and sphingomyeline (around 14\%) (Fournier et al., 1997). We have thus analysed the effect of 5 abundant molecular species of PC, which are present in HDL of healthy volunteers (Pruzanski et al., 2000) and differ by their fatty acid composition: 1-palmitoyl-2-linoleyl-phosphatidylcholine (PLPC), 1- palmitoyl-2oleyl-phosphatidylcholine (POPC), 1-stearoyl-2-linoleyl-phosphatidylcholine (SLPC), 1-palmitoyl-2arachidonoyl-phosphatidylcholine (PAPC) and dipalmitoyl-phosphatidylcholine (PPPC). Synthetic lipids were used because their fatty acid composition is strictly determined. PC treatment did not affect the phenotype of mature DCs (data not shown). Their effect was also analysed on the functional ability of DCs to activate T cells, as previously. PLPC and SLPC had the most potent inhibitory effect on the Th1 function of LPS-stimulated DCs whereas PPPC had the weakest impact (Fig. 4B). PAPC and POPC had a modest inhibitory effect that was dependent on DC donor. To further validate the differential function of these molecular species of PL, PLPC was chosen as the archetype of a strong inhibitory PL and PPPC as the archetype of a weak inhibitory PL. In mean of 5 distinct experiments, PLPC pre-treatment reduced by $60 \%$ the ability of mature DCs to stimulate IFN $\gamma$ secretion by T cells whereas PPPC only induced a $16 \%$ reduction of IFN $\gamma$ secretion that was not statistically significant (Fig. 4C).

Since TLR4 signalling in DC results in the activation of the nuclear factor (NF)- $\kappa B$, we analysed its binding activity in EMSA assays, using a specific DNA probe. In DCs harvested $24 \mathrm{~h}$ after induction of maturation, LPS treatment resulted in a 50\% increase of NF- $\kappa B$ activity compared to control DCs (Fig. 4D). When cells were pre-treated with PLPC, NF-אB activation by LPS was importantly reduced whereas PPPC had no significant impact. This reduction of NF- $\mathrm{BB}$ activation by PLPC pre-treatment was associated with a reduced secretion of IL-12, TNF- $\alpha$ and IL-6 whereas IL-10 and IL-8 secretion was not affected (Supplementary Fig. 1). 


\section{Discussion}

We have shown that LDL and HDL can interfere with DC maturation triggered by TLR stimulation, impairing the ability of DC to stimulate a Th1 response, reducing the amount of IFN $\gamma$ secreted by T cells. We did not observe a Th2 shift of DC function, characterized by an increase in IL-10 secretion by DC or IL-5 and IL-13 secretion by stimulated T cells (Agaugue et al., 2006). HDL had the highest inhibitory impact on the Th1 function of mature DC and only HDL but not LDL pre-treatment of DC induced a slight reduction of IL-12 secretion. Although IL-12 decreased secretion could account for a decreased Th1 function of DC, other mechanisms are likely to be involved since a strict correlation between the inhibition of IL-12 secretion and the decreased Th1 function was not observed. We also showed that the lipid moiety of HDL presented the same inhibitory potential as native HDL. To identify the immunomodulatory lipids, the different classes of HDL lipids were separated and their impact on DC maturation was tested. PL from HDL could strongly impair the ability of DC to induce a Th1 response of $\mathrm{T}$ cells. Depending on their fatty acid composition, synthetic PCs had various inhibitory potential ranging from low not statistically significant for PPPC to high inhibitory activity for PLPC and SLPC. PAPC and POPC could moderately inhibit the Th1 function of DC. PLPC representing 30 to $40 \%$ of total PC in normal HDL (Pruzanski et al., 2000) may largely contribute to the inhibitory activity of HDL. It has been recently shown that VLDL, LDL and HDL presented specific species pattern of phospholipids characterized by their fatty acid composition (Wiesner et al., 2009). Although the impact of LDL and HDL on DC function cannot be reduced to the effect of PC, the fatty acid composition of lipoprotein lipids is probably an important key controlling their physiological function.

Neither LDL nor HDL or lipids from HDL affected the phenotypic maturation induced by TLR ligands. They only modulated the functional properties of DC without preventing maturation. Therefore, their action has to be distinguished from that of maturation inhibitors, such as dextran sulphate (Spirig et al., 2008). This is an important point indicating that LDL and HDL do not inhibit LPS signalling by passive adsorption in the experimental conditions used. Moreover, to avoid adsorption, LPS was introduced in DC culture 24h or 48h after lipoproteins or lipids. Pre-treatment of 
DC by PLPC $24 \mathrm{~h}$ or $48 \mathrm{~h}$ before LPS stimulation efficiently inhibited the ability of DC to induce IFN $\gamma$ secretion by $\mathrm{T}$ cells, whereas PLPC added concomitantly to LPS had no effect, suggesting that PLPC induced by itself some modifications altering the ability of DC to respond to TLR stimulation (data not shown).

This alteration of signalling could result from a reduced TLR clustering. The accessory molecule MD2, which is expressed on DC, is necessary for the clustering of TLR4 in lipid rafts and an efficient signalling (Kobayashi et al., 2006; Triantafilou et al., 2004). A specific phosphatidylserine has been reported to inhibit TLR clustering in lipid rafts (Parker et al., 2008). Oxidized PAPC could also inhibit TLR2 and TLR4 signalling mainly by competition with the ligands for the binding on accessory proteins such as MD-2 (Erridge et al., 2008; Walton et al., 2003a; Walton et al., 2003b; Walton et al., 2006). All these results were obtained when lipids and TLR ligands were introduced concomitantly. We explored the direct binding competition hypothesis using the human embryonic kidney 293TLR4/MD2-CD14 cell line but observed no significant inhibition of the LPS response when these cells were treated by HDL or PLPC thirty minutes prior to LPS stimulation (data not shown), suggesting the absence of direct competition for receptor binding. Therefore, our results are not in favour of an alteration of TLR clustering by lipoproteins.

Most likely, LDL, HDL and lipids from HDL provide signals to DCs that alter the ability of the cells to respond to LPS by modulating downstream signalling cascade. DCs express numerous receptors for lipoproteins. LDL-R and LDLR-related protein (LRP, CD91) can endocytose lipoproteins through apoE or apoB interactions (Mahley and Rall, 2000; van den Elzen et al., 2005). Scavenger receptors bind and internalize a variety of ligands including lipoproteins and provide signals that can modulate the inflammatory and immune responses (Areschoug and Gordon, 2009; Kzhyshkowska and Krusell, 2009). Among the scavenger receptors expressed by DCs, non-modified LDL and HDL can bind to class B scavenger receptors SR-BI or CD36. SR-BI has been shown to activate PI3K, resulting in the phosphorylation of ERK and Akt (Al-Jarallah and Trigatti, 2010; Saddar et al., 2010). CD36 has been found to cooperate with members of the TLR family such as TLR2, TLR4 and TLR6 to activate innate immune responses (Hoebe et al., 2005; Stewart et al., 2010; Stuart et al., 2005). TLR can use different adaptor molecules, following distinct intracellular signalling pathways. We observed that 
HDL can interfere with the functional maturation of DC triggered by the ligands of TLR4 (LPS), TLR1/2 (Pam) and TLR2/6 (PGN) whereas no similar effect was observed with TLR3 ligand (data not shown). TLR4, TLR1/2 and TLR2/6 share the ability to recruit the MyD88 adaptor, initiating a signalling pathway that results in the activation of MAP kinases and the transcription factor NF- $\mathrm{kB}$, leading to the production of pro-inflammatory cytokines such as TNF- $\alpha$, IL-6 and IL-12 (Takeda and Akira, 2004). TLR3 signalling mainly uses the Toll/IL-1R domain-containing adaptor inducing IFN- $\beta$ (TRIF) adaptor, activating a pathway resulting in IFN regulatory factor-3 activation and IFN- $\beta$ synthesis. TLR4 has the unique ability to stimulate both the MyD88-dependent pathway and the TRIF-dependent pathway. Therefore, our results suggest that HDL could interfere with the MyD88dependent pathway.

The most effective PLs in inhibiting DC function (PLPC and SLPC), both contain a linoleic acid esterified at the Sn-2 position and the ability of lipoproteins to inhibit DC function seems to be correlated to the percentage of linoleic acid in total fatty acids (Supplementary Fig. 2). Interestingly, lipid peroxidation of the polyunsaturated linoleic acid generates some 9- and 13-HODE (hydroxyoctadecadienoic acid) which are activating ligands of PPAR $\gamma$. Our previous results showed that the Th1 function of DC is regulated by PPAR $\gamma$ activity and that 9/13-HODE can prevent mature DC to acquire a Th1 function without affecting its phenotype (Coutant et al., 2004). Moreover, the activation of PPAR $\gamma$ during DC differentiation results in a reduced NF- $\kappa B$ activation upon TLR stimulation by LPS (Appel et al., 2005). Our preliminary results indicate that PLPC-treatment of DC enhanced PPAR $\gamma$ DNA-binding activity with a good efficiency compared to 9-HODE (Supplementary Fig. 3). Zapata-Gonzalez et al. have also shown that free linoleate inhibited IL-12 secretion by LPSstimulated DC and polyunsaturated fatty acids down-regulated the ability of DC to stimulate T cells mainly through PPAR $\gamma$ activation (Zapata-Gonzalez et al., 2008). Moreover, we observed that PLPC but not PPPC induced an increased phosphorylation of ERK upon LPS stimulation (data not shown). Interestingly, we and others have previously shown that increased ERK phosphorylation can inhibit the Th1 functional maturation of DC by reducing NF- $\kappa \mathrm{B}$ activation and IL-12 secretion (Agaugue et al., 2006; Agaugue et al., 2007; Loscher et al., 2005; Perrin-Cocon et al., 2008; Puig-Kroger et al., 
2001). Our preliminary data suggest that PLPC may impair the functional maturation of DC via increased activation of PPAR $\gamma$ and ERK, inducing some changes in the functional status of DC resulting in altered TLR signalling.

The results shown here provide more evidence that lipoproteins can modulate DC function (Angeli et al., 2004; Yu et al., 2010). In vivo, DCs infiltrating the peripheral tissues can detect microorganism compounds via TLRs and other receptors of pathogen-associated microorganism patterns. TLR activation engages a maturation process inducing DC migration to draining lymph nodes where mature DCs can stimulate T cells. Lipoproteins that penetrate the peripheral tissues could modulate DC response to TLR stimulation, thus altering the following $\mathrm{T}$ cell stimulation. This modulation would tightly depend on the lipoprotein composition within the tissue and lipoprotein potential modifications such as oxidation that occur in inflammatory tissues. Similarly to the situation within tissues, the lipoprotein concentration used in this study is reduced compared to the high concentration of circulating lipoproteins. Lipoprotein concentration within tissues can increase in pathological conditions such as atherosclerosis where high amounts of modified lipoproteins such as oxLDL accumulate (Perrin-Cocon et al., 2001). We previously found that oxLDL and its major component LPC induced the maturation of DCs that acquired a Th1 function, whereas native LDL inhibited the maturation of DC triggered by oxLDL or LPC. Therefore the balance between oxLDL and LDL can regulate DC function (Coutant et al., 2002; Coutant et al., 2004; Perrin-Cocon et al., 2001). Numerous previous studies have described the major role of HDL to control LDL oxidation, therefore playing an indirect role in the regulation of immune function. The results presented in this article indicate that LDL and HDL have the ability to down regulate directly the functional maturation of DC triggered by some TLR stimulations.

This inhibition by HDL of the Th1 DC function provides another mechanism in support to the antiinflammatory properties of HDL. Depending on the biochemical composition of LDL and HDL, these lipoproteins may differently impact DC function. PLs from HDL can be detected by DCs and provide signals regulating their response. Therefore, in addition to their essential role in metabolism, HDL and LDL are active lipoproteins involved in the control of the immune system. An intriguing consequence of this activity is that, under normal conditions, dense lipoproteins could contribute to the prevention 
of non-specific immune reactions by elevating the activation threshold of the immune system. During pathological conditions, the transient lowering of HDL levels or modifications altering their function may favour DC activation. The persistence of these modifications could promote chronic stimulation of the immune system and the development of chronic inflammatory diseases. During atherosclerosis, modifications of HDL affecting their functionality could favour the development of pro-inflammatory responses by concomitantly lowering the activation threshold of the immune system and allowing the accumulation of oxLDL. 


\section{Acknowledgements}

This study was supported by the Institut National de la Santé et de la Recherche Médicale (Inserm) and the Agence Nationale pour la Recherche sur le SIDA et les hépatites (ANRS).

The authors have no financial support or relationship that may pose conflict of interest. 


\section{References}

Agaugue, S., Perrin-Cocon, L., Coutant, F., Andre, P., Lotteau, V., 2006. 1-Methyl-tryptophan can interfere with TLR signaling in dendritic cells independently of IDO activity. J. Immunol. $177,2061-2071$.

Agaugue, S., Perrin-Cocon, L., Andre, P., Lotteau, V., 2007. Hepatitis C Lipo-Viro-Particle from Chronically Infected Patients Interferes with TLR4 Signaling in Dendritic Cell. PLoS ONE 2, e330.

Al-Jarallah, A., Trigatti, B. L., 2010. A role for the scavenger receptor, class B type I in high density lipoprotein dependent activation of cellular signaling pathways. Biochim. Biophys. Acta $1801,1239-1248$.

Angeli, V., Llodra, J., Rong, J. X., Satoh, K., Ishii, S., Shimizu, T., Fisher, E. A., Randolph, G. J., 2004. Dyslipidemia associated with atherosclerotic disease systemically alters dendritic cell mobilization. Immunity 21, 561-574.

Appel, S., Mirakaj, V., Bringmann, A., Weck, M. M., Grunebach, F., Brossart, P., 2005. PPARgamma agonists inhibit toll-like receptor-mediated activation of dendritic cells via the MAP kinase and NF-kappaB pathways. Blood 106, 3888-3894.

Areschoug, T., Gordon, S., 2009. Scavenger receptors: role in innate immunity and microbial pathogenesis. Cell. Microbiol. 11, 1160-1169.

Barter, P., 2005. The inflammation: lipoprotein cycle. Atheroscler. Suppl 6, 15-20.

Coutant, F., Perrin-Cocon, L., Agaugue, S., Delair, T., Andre, P., Lotteau, V., 2002. Mature dendritic cell generation promoted by lysophosphatidylcholine. J. Immunol. 169, 1688-1695.

Coutant, F., Agaugue, S., Perrin-Cocon, L., Andre, P., Lotteau, V., 2004. Sensing environmental lipids by dendritic cell modulates its function. J. Immunol. 172, 54-60.

Erridge, C., Kennedy, S., Spickett, C. M., Webb, D. J., 2008. Oxidized phospholipid inhibition of tolllike receptor (TLR) signaling is restricted to TLR2 and TLR4: roles for CD14, LPS-binding protein, and MD2 as targets for specificity of inhibition. J. Biol. Chem. 283, 24748-24759. 
Folch, J., Lees, M., Sloane Stanley, G. H., 1957. A simple method for the isolation and purification of total lipides from animal tissues. J. Biol. Chem. 226, 497-509.

Fournier, N., Paul, J. L., Atger, V., Cogny, A., Soni, T., de la Llera-Moya, M., Rothblat, G., Moatti, N., 1997. HDL phospholipid content and composition as a major factor determining cholesterol efflux capacity from Fu5AH cells to human serum. Arterioscler. Thromb. Vasc. Biol. 17, 2685-2691.

Gupta, S., Pablo, A. M., Jiang, X., Wang, N., Tall, A. R., Schindler, C., 1997. IFN-gamma potentiates atherosclerosis in ApoE knock-out mice. J. Clin. Invest. 99, 2752-2761.

Hansson, G. K., Holm, J., Jonasson, L., 1989. Detection of activated T lymphocytes in the human atherosclerotic plaque. Am. J. Pathol. 135, 169-175.

Havel, R. J., Eder, H. A., Bragdon, J. H., 1955. The distribution and chemical composition of ultracentrifugally separated lipoproteins in human serum. J. Clin. Invest. 34, 1345-1353.

Hoebe, K., Georgel, P., Rutschmann, S., Du, X., Mudd, S., Crozat, K., Sovath, S., Shamel, L., Hartung, T., Zahringer, U., Beutler, B., 2005. CD36 is a sensor of diacylglycerides. Nature $433,523-527$.

Jahangiri, A., de Beer, M. C., Noffsinger, V., Tannock, L. R., Ramaiah, C., Webb, N. R., van der Westhuyzen, D. R., de Beer, F. C., 2009. HDL remodeling during the acute phase response. Arterioscler. Thromb. Vasc. Biol. 29, 261-267.

Kates, M., 1986. Techniques of Lipidology: Isolation, Analysis, and Identification of Lipids. In: Burden, R., and van Kippenburg, P. (Eds.), Laboratory Techniques in Biochemistry and Molecular Biology. Elsevier Science Ltd, New York, pp. 232-254.

Kobayashi, M., Saitoh, S., Tanimura, N., Takahashi, K., Kawasaki, K., Nishijima, M., Fujimoto, Y., Fukase, K., Akashi-Takamura, S., Miyake, K., 2006. Regulatory roles for MD-2 and TLR4 in ligand-induced receptor clustering. J. Immunol. 176, 6211-6218.

Kume, N., Cybulsky, M. I., Gimbrone, M. A., Jr., 1992. Lysophosphatidylcholine, a component of atherogenic lipoproteins, induces mononuclear leukocyte adhesion molecules in cultured human and rabbit arterial endothelial cells. J. Clin. Invest. 90, 1138-1144. 
Kzhyshkowska, J., Krusell, L., 2009. Cross-talk between endocytic clearance and secretion in macrophages. Immunobiology 214, 576-593.

Laurat, E., Poirier, B., Tupin, E., Caligiuri, G., Hansson, G. K., Bariety, J., Nicoletti, A., 2001. In vivo downregulation of $\mathrm{T}$ helper cell 1 immune responses reduces atherogenesis in apolipoprotein E-knockout mice. Circulation 104, 197-202.

Lee, T. S., Yen, H. C., Pan, C. C., Chau, L. Y., 1999. The role of interleukin 12 in the development of atherosclerosis in ApoE-deficient mice. Arterioscler. Thromb. Vasc. Biol. 19, 734-742.

Lewis, G. F., Rader, D. J., 2005. New insights into the regulation of HDL metabolism and reverse cholesterol transport. Circ. Res. 96, 1221-1232.

Loscher, C. E., Draper, E., Leavy, O., Kelleher, D., Mills, K. H., Roche, H. M., 2005. Conjugated linoleic acid suppresses NF-kappa B activation and IL-12 production in dendritic cells through ERK-mediated IL-10 induction. J. Immunol. 175, 4990-4998.

Mahley, R. W., Rall, S. C., Jr., 2000. Apolipoprotein E: far more than a lipid transport protein. Annu. Rev. Genomics Hum. Genet. 1, 507-537.

McMahon, M., Grossman, J., FitzGerald, J., Dahlin-Lee, E., Wallace, D. J., Thong, B. Y., Badsha, H., Kalunian, K., Charles, C., Navab, M., Fogelman, A. M., Hahn, B. H., 2006. Proinflammatory high-density lipoprotein as a biomarker for atherosclerosis in patients with systemic lupus erythematosus and rheumatoid arthritis. Arthritis Rheum. 54, 2541-2549.

Murphy, A. J., Woollard, K. J., Hoang, A., Mukhamedova, N., Stirzaker, R. A., McCormick, S. P., Remaley, A. T., Sviridov, D., Chin-Dusting, J., 2008. High-density lipoprotein reduces the human monocyte inflammatory response. Arterioscler. Thromb. Vasc. Biol. 28, 2071-2077.

Nagano, H., Mitchell, R. N., Taylor, M. K., Hasegawa, S., Tilney, N. L., Libby, P., 1997. Interferongamma deficiency prevents coronary arteriosclerosis but not myocardial rejection in transplanted mouse hearts. J. Clin. Invest. 100, 550-557.

Navab, M., Imes, S. S., Hama, S. Y., Hough, G. P., Ross, L. A., Bork, R. W., Valente, A. J., Berliner, J. A., Drinkwater, D. C., Laks, H., et al., 1991. Monocyte transmigration induced by modification of low density lipoprotein in cocultures of human aortic wall cells is due to 
induction of monocyte chemotactic protein 1 synthesis and is abolished by high density lipoprotein. J. Clin. Invest. 88, 2039-2046.

Navab, M., Reddy, S. T., Van Lenten, B. J., Anantharamaiah, G. M., Fogelman, A. M., 2009. The role of dysfunctional HDL in atherosclerosis. J. Lipid Res. 50 Suppl, S145-149.

Niessner, A., Weyand, C. M., 2010. Dendritic cells in atherosclerotic disease. Clin. Immunol. 134, 2532.

Norata, G. D., Callegari, E., Marchesi, M., Chiesa, G., Eriksson, P., Catapano, A. L., 2005. Highdensity lipoproteins induce transforming growth factor-beta2 expression in endothelial cells. Circulation 111, 2805-2811.

Parker, L. C., Prestwich, E. C., Ward, J. R., Smythe, E., Berry, A., Triantafilou, M., Triantafilou, K., Sabroe, I., 2008. A phosphatidylserine species inhibits a range of TLR- but not IL-1betainduced inflammatory responses by disruption of membrane microdomains. J. Immunol. 181, $5606-5617$.

Perrin-Cocon, L., Coutant, F., Agaugue, S., Deforges, S., Andre, P., Lotteau, V., 2001. Oxidized lowdensity lipoprotein promotes mature dendritic cell transition from differentiating monocyte. J. Immunol. 167, 3785-3791.

Perrin-Cocon, L., Agaugue, S., Coutant, F., Saint-Mezard, P., Guironnet-Paquet, A., Nicolas, J. F., Andre, P., Lotteau, V., 2006. Lysophosphatidylcholine is a natural adjuvant that initiates cellular immune responses. Vaccine 24, 1254-1263.

Perrin-Cocon, L., Agaugue, S., Diaz, O., Vanbervliet, B., Dollet, S., Guironnet-Paquet, A., Andre, P., Lotteau, V., 2008. Th1 disabled function in response to TLR4 stimulation of monocytederived DC from patients chronically-infected by hepatitis C virus. PLoS ONE 3, e2260.

Pruzanski, W., Stefanski, E., de Beer, F. C., de Beer, M. C., Ravandi, A., Kuksis, A., 2000. Comparative analysis of lipid composition of normal and acute-phase high density lipoproteins. J. Lipid Res. 41, 1035-1047.

Puig-Kroger, A., Relloso, M., Fernandez-Capetillo, O., Zubiaga, A., Silva, A., Bernabeu, C., Corbi, A. L., 2001. Extracellular signal-regulated protein kinase signaling pathway negatively 
regulates the phenotypic and functional maturation of monocyte-derived human dendritic cells. Blood 98, 2175-2182.

Raisanen-Sokolowski, A., Glysing-Jensen, T., Koglin, J., Russell, M. E., 1998. Reduced transplant arteriosclerosis in murine cardiac allografts placed in interferon-gamma knockout recipients. Am. J. Pathol. 152, 359-365.

Randolph, G. J., Beaulieu, S., Lebecque, S., Steinman, R. M., Muller, W. A., 1998. Differentiation of monocytes into dendritic cells in a model of transendothelial trafficking. Science 282, 480483.

Saddar, S., Mineo, C., Shaul, P. W., 2010. Signaling by the high-affinity HDL receptor scavenger receptor B type I. Arterioscler. Thromb. Vasc. Biol. 30, 144-150.

Scanu, A. M., Edelstein, C., 2008. HDL: bridging past and present with a look at the future. Faseb J. $22,4044-4054$.

Shamshiev, A. T., Ampenberger, F., Ernst, B., Rohrer, L., Marsland, B. J., Kopf, M., 2007. Dyslipidemia inhibits Toll-like receptor-induced activation of CD8alpha-negative dendritic cells and protective Th1 type immunity. J. Exp. Med. 204, 441-452.

Spirig, R., van Kooten, C., Obregon, C., Nicod, L., Daha, M., Rieben, R., 2008. The complement inhibitor low molecular weight dextran sulfate prevents TLR4-induced phenotypic and functional maturation of human dendritic cells. J. Immunol. 181, 878-890.

Stewart, C. R., Stuart, L. M., Wilkinson, K., van Gils, J. M., Deng, J., Halle, A., Rayner, K. J., Boyer, L., Zhong, R., Frazier, W. A., Lacy-Hulbert, A., El Khoury, J., Golenbock, D. T., Moore, K. J., 2010. CD36 ligands promote sterile inflammation through assembly of a Toll-like receptor 4 and 6 heterodimer. Nat. Immunol. 11, 155-161.

Stuart, L. M., Deng, J., Silver, J. M., Takahashi, K., Tseng, A. A., Hennessy, E. J., Ezekowitz, R. A., Moore, K. J., 2005. Response to Staphylococcus aureus requires CD36-mediated phagocytosis triggered by the COOH-terminal cytoplasmic domain. J. Cell Biol. 170, 477485. 
Sviridov, D., Mukhamedova, N., Remaley, A. T., Chin-Dusting, J., Nestel, P., 2008. Antiatherogenic functionality of high density lipoprotein: how much versus how good. J. Atheroscler. Thromb. 15, 52-62.

Takeda, K., Akira, S., 2004. TLR signaling pathways. Semin. Immunol. 16, 3-9.

Triantafilou, M., Brandenburg, K., Kusumoto, S., Fukase, K., Mackie, A., Seydel, U., Triantafilou, K., 2004. Combinational clustering of receptors following stimulation by bacterial products determines lipopolysaccharide responses. Biochem. J. 381, 527-536.

van den Elzen, P., Garg, S., Leon, L., Brigl, M., Leadbetter, E. A., Gumperz, J. E., Dascher, C. C., Cheng, T. Y., Sacks, F. M., Illarionov, P. A., Besra, G. S., Kent, S. C., Moody, D. B., Brenner, M. B., 2005. Apolipoprotein-mediated pathways of lipid antigen presentation. Nature 437, 906-910.

Van Lenten, B. J., Hama, S. Y., de Beer, F. C., Stafforini, D. M., McIntyre, T. M., Prescott, S. M., La Du, B. N., Fogelman, A. M., Navab, M., 1995. Anti-inflammatory HDL becomes proinflammatory during the acute phase response. Loss of protective effect of HDL against LDL oxidation in aortic wall cell cocultures. J. Clin. Invest. 96, 2758-2767.

van Leuven, S. I., Hezemans, R., Levels, J. H., Snoek, S., Stokkers, P. C., Hovingh, G. K., Kastelein, J. J., Stroes, E. S., de Groot, E., Hommes, D. W., 2007. Enhanced atherogenesis and altered high density lipoprotein in patients with Crohn's disease. J. Lipid Res. 48, 2640-2646.

Wadham, C., Albanese, N., Roberts, J., Wang, L., Bagley, C. J., Gamble, J. R., Rye, K. A., Barter, P. J., Vadas, M. A., Xia, P., 2004. High-density lipoproteins neutralize C-reactive protein proinflammatory activity. Circulation 109, 2116-2122.

Walton, K. A., Cole, A. L., Yeh, M., Subbanagounder, G., Krutzik, S. R., Modlin, R. L., Lucas, R. M., Nakai, J., Smart, E. J., Vora, D. K., Berliner, J. A., 2003a. Specific phospholipid oxidation products inhibit ligand activation of toll-like receptors 4 and 2. Arterioscler. Thromb. Vasc. Biol. 23, 1197-1203.

Walton, K. A., Hsieh, X., Gharavi, N., Wang, S., Wang, G., Yeh, M., Cole, A. L., Berliner, J. A., 2003b. Receptors involved in the oxidized 1-palmitoyl-2-arachidonoyl-sn-glycero-3- 
phosphorylcholine-mediated synthesis of interleukin-8. A role for Toll-like receptor 4 and a glycosylphosphatidylinositol-anchored protein. J. Biol. Chem. 278, 29661-29666.

Walton, K. A., Gugiu, B. G., Thomas, M., Basseri, R. J., Eliav, D. R., Salomon, R. G., Berliner, J. A., 2006. A role for neutral sphingomyelinase activation in the inhibition of LPS action by phospholipid oxidation products. J. Lipid Res. 47, 1967-1974.

Wiesner, P., Leidl, K., Boettcher, A., Schmitz, G., Liebisch, G., 2009. Lipid profiling of FPLCseparated lipoprotein fractions by electrospray ionization tandem mass spectrometry. J. Lipid Res. 50, 574-585.

Yu, B. L., Wang, S. H., Peng, D. Q., Zhao, S. P., 2010. HDL and immunomodulation: an emerging role of HDL against atherosclerosis. Immunol. Cell Biol. 88, 285-290.

Zapata-Gonzalez, F., Rueda, F., Petriz, J., Domingo, P., Villarroya, F., Diaz-Delfin, J., de Madariaga, M. A., Domingo, J. C., 2008. Human dendritic cell activities are modulated by the omega-3 fatty acid, docosahexaenoic acid, mainly through PPAR(gamma):RXR heterodimers: comparison with other polyunsaturated fatty acids. J. Leukoc. Biol. 84, 1172-1182. 


\section{Figure Legends}

Fig. 1. Dense lipoproteins interfere with TLR4-induced functional maturation of DCs. (A) Experimental design: DCs were differentiated from blood monocytes from healthy donors with GMCSF and IL-4 and these cells were treated at day 4 with lipoproteins at $50 \mu \mathrm{g} / \mathrm{ml}$ of phospholipids prior TLR stimulation at day 5 for 24h. Control immature DCs were obtained at day 6 without any addition. DCs harvested at day 6 were cocultured in triplicates for 5 days with allogeneic $\mathrm{T}$ cells (MLR) at a 1/10 DC/T cells ratio. IFN $\gamma$ was assayed in coculture supernatant using CBA Flex sets. (B) Phenotype of DCs at day 6. (C) IFN $\gamma$ secretion in MLR supernatants. The mean secretion for culture triplicates was normalized to LPS-treated DCs for each experiment. Bars indicate mean +/- SD for 7 experiments. (D) IL-12 secretion by DCs at the end of the maturation process. The cytokine was measured in DC supernatants collected at day 6 by ELISA detecting IL-12p40 chain and secretion was normalized to LPS-treated DCs in each experiment. The mean +/- SD of 7 experiments is shown. $* \mathrm{p}<0.05 * * \mathrm{p}<0.03$, compared to the LPS control group in a pairwise student's test

Fig. 2. HDL interferes with LPS, PGN and PAM-stimulated maturation of DCs. DCs were treated at day 4 with HDL, prior to stimulation at day 5 for 24 h by LPS, PGN or PAM. DCs harvested at day 6 were cocultured in triplicates for 5 days with allogeneic T cells at a ratio of $1 / 10 \mathrm{DC} / \mathrm{T}$ cells. IFN $\gamma$ was assayed in coculture supernatant using CBA Flex sets. (A) HDL inhibition of LPS-induced maturation is dose-dependent. DCs were pre-treated with HDL at 50,20 , or $2 \mu \mathrm{g} / \mathrm{ml}$ of PL prior to LPS stimulation. Bars indicate the mean IFN $\gamma$ secretion $+/-\mathrm{SD}$ of triplicates for one representative experiment out of 3. (B-C) DCs were treated with $50 \mu \mathrm{g} / \mathrm{ml} \mathrm{HDL}$ at day 4, before stimulation by LPS, PGN or PAM. Mean IFN $\gamma$ secretion of triplicates of 4 experiments is shown. (B) The outlier box plot shows a rectangular box from the first to the third quartile, with the median marked by a line inside the box and whiskers extending to the furthest observations. The mean is indicated by the outside line. (C) Mean IFN $\gamma$ secretion of triplicates was normalized to LPS-treated DCs for each experiment and the mean percentage inhibition by HDL $+/-$ SD is indicated. 
$* \mathrm{p}<0.05$ in a pairwise student's test

Fig. 3. Regulation of DC functions by lipids extracted from HDL. DCs were treated at day 4 with HDL (50 $\mu \mathrm{g} / \mathrm{ml}$ of PL), total lipids extracted from HDL (50 $\mu \mathrm{g} / \mathrm{ml}$ of PL), PL extracted from HDL (10 $\mu \mathrm{g} / \mathrm{ml}$ ), TG or CE extracted from HDL (equivalent concentration to HDL), prior to LPS stimulation at day 5 for $24 \mathrm{~h}$. (A) DCs harvested at day 6 were cocultured in triplicates for 5 days with allogeneic $\mathrm{T}$ cells at a ratio of $1 / 10 \mathrm{DC} / \mathrm{T}$ cells. IFN $\gamma$ was assayed in coculture supernatant using CBA Flex sets. Mean IFN $\gamma$ secretion of triplicates was normalized to LPS-treated DCs for each experiment. The inhibition percentage of IFN $\gamma$ secretion by HDL or lipids is shown for 5 independent experiments. The outlier box plot shows a rectangular box from the first to the third quartile, with the median marked in the centre and whiskers extending to the furthest observations. (B) DC supernatants collected at day 6 were assayed for IL-12p40 secretion. Bars indicate the mean secretion +/- SD for 4 independent experiments.

$* \mathrm{p}<0.05 * * \mathrm{p}<0.02$, compared to the LPS control group in a pairwise student's test

Fig. 4. Identification of PL inhibiting DC ability to stimulate T cells. DCs were treated at day 4 with 10,5 or $2.5 \mu \mathrm{g} / \mathrm{ml}$ PL extracted from HDL (A) or synthetic PL (B-D) at 10 or $1 \mu \mathrm{g} / \mathrm{ml}$ (B) or $10 \mu \mathrm{g} / \mathrm{ml}$ (C-D), prior to LPS stimulation at day 5 for $24 \mathrm{~h}$. DCs were harvested at day 6. (A-C) DCs were cocultured in triplicates for 5 days with allogeneic T cells at a ratio of $1 / 10 \mathrm{DC} / \mathrm{T}$ cells. IFN $\gamma$ was assayed in coculture supernatant using CBA Flex kit. (A-B) Mean IFN $\gamma$ secretion +/- SD of triplicates is shown for one representative experiment out of 3. (C) The mean secretion for coculture triplicates was normalized to LPS-treated DCs for each experiment. Bars indicate the mean +/- SD for 5 experiments. (D) Nuclear extracts were prepared from harvested cells and the binding activity of NF$\kappa \mathrm{B}$ was measured by EMSA using a ${ }^{32} \mathrm{P}$-labeled specific probe. The increase in NF- $\kappa \mathrm{B}$ activity compared to control immature DCs is expressed in percentage of the control and the mean +/- SD for 3 independent experiments is shown.

$* \mathrm{p}<0.05 * * \mathrm{p}<0.02$, compared to the LPS control group in a pairwise student's test 


\section{Table 1}

Lipid composition of lipoproteins

\begin{tabular}{cccc}
\hline Lipoprotein $^{1}$ & PL $(\mu \mathrm{g} / \mathrm{ml})$ & $\mathrm{TG}(\mu \mathrm{g} / \mathrm{ml})$ & Chol $(\mu \mathrm{g} / \mathrm{ml})$ \\
\hline VLDL & 50 & $140 \pm 33$ & $54 \pm 8$ \\
LDL & 50 & $16 \pm 3$ & $94 \pm 11$ \\
HDL & 50 & $14 \pm 7$ & $59 \pm 22$ \\
\hline
\end{tabular}

${ }^{1}$ Concentration in phospholipids (PL), triglycerides (TG) and total cholesterol (Chol) introduced in the culture medium by addition of VLDL, LDL or HDL at $50 \mu \mathrm{g} / \mathrm{ml}$ of PL. The mean \pm SD for 7 lipoprotein donors is indicated. 


\section{(A) Monocytes}

Day 0 Differentiation with GM-CSF and IL-4

DCs $+\mathrm{T}$ cells

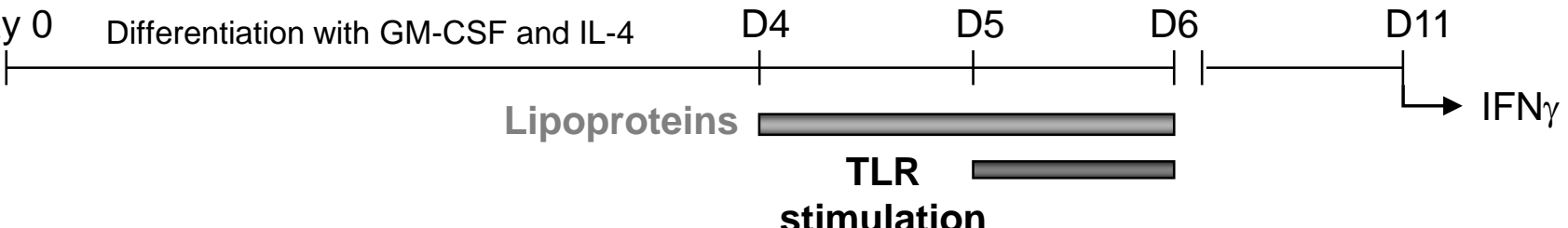

(B)
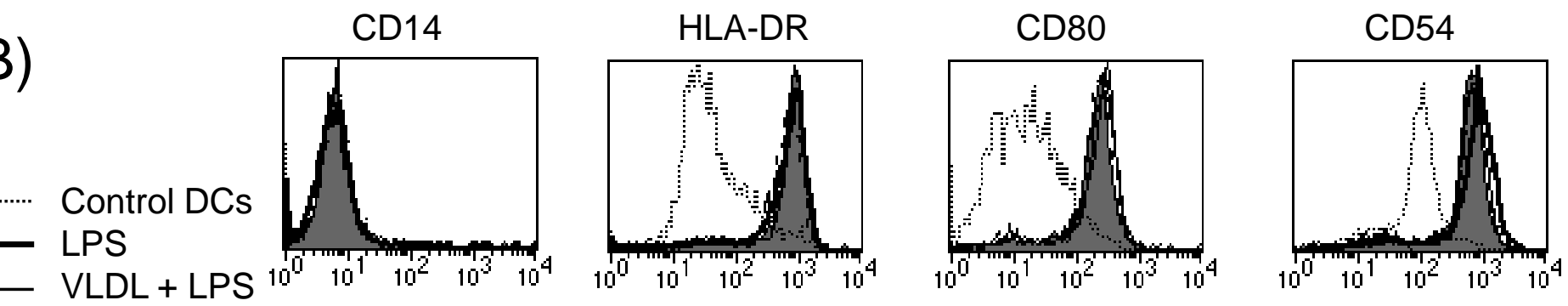

-.. LDL + LPS

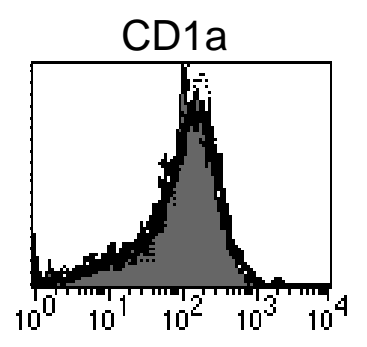

(C)
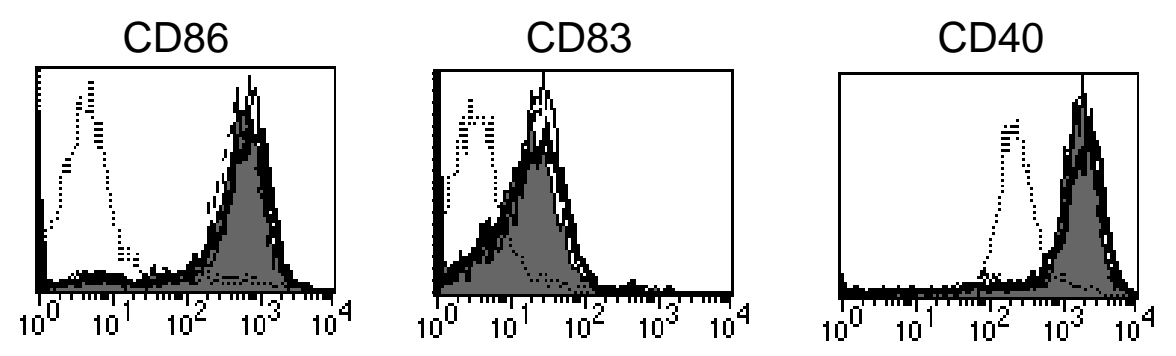

(D)
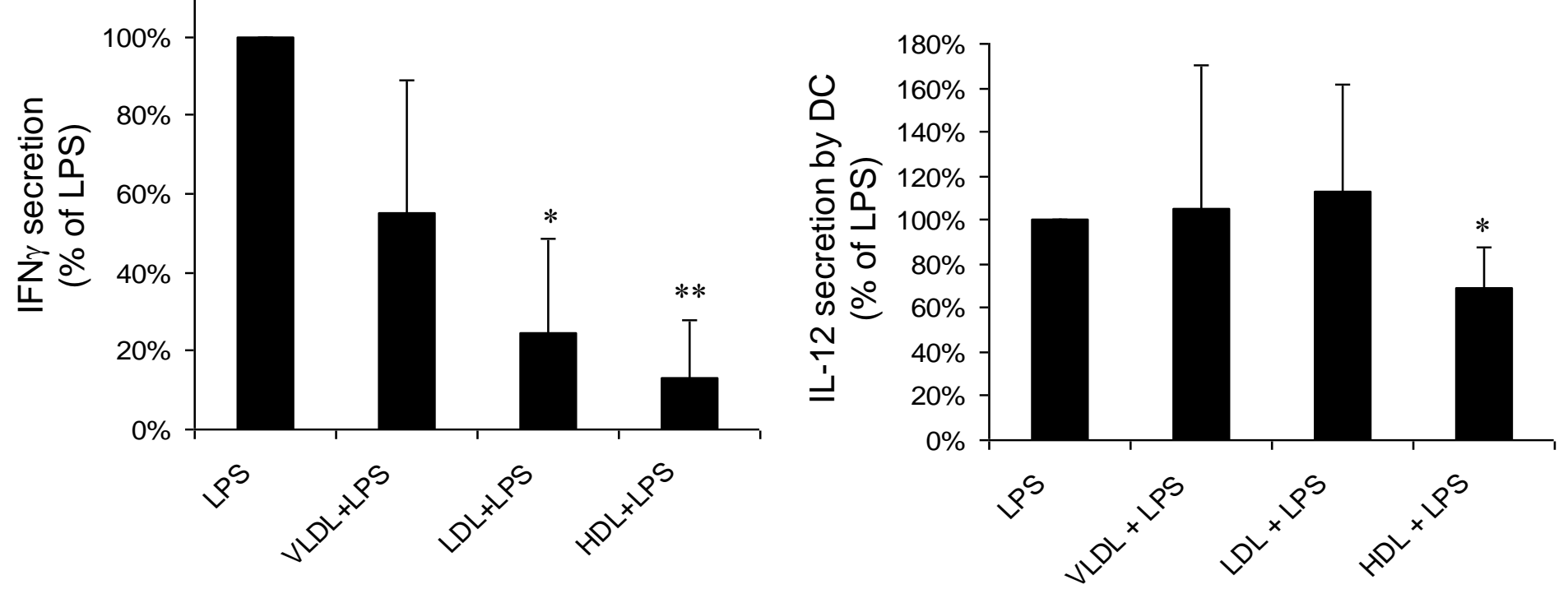
(A)

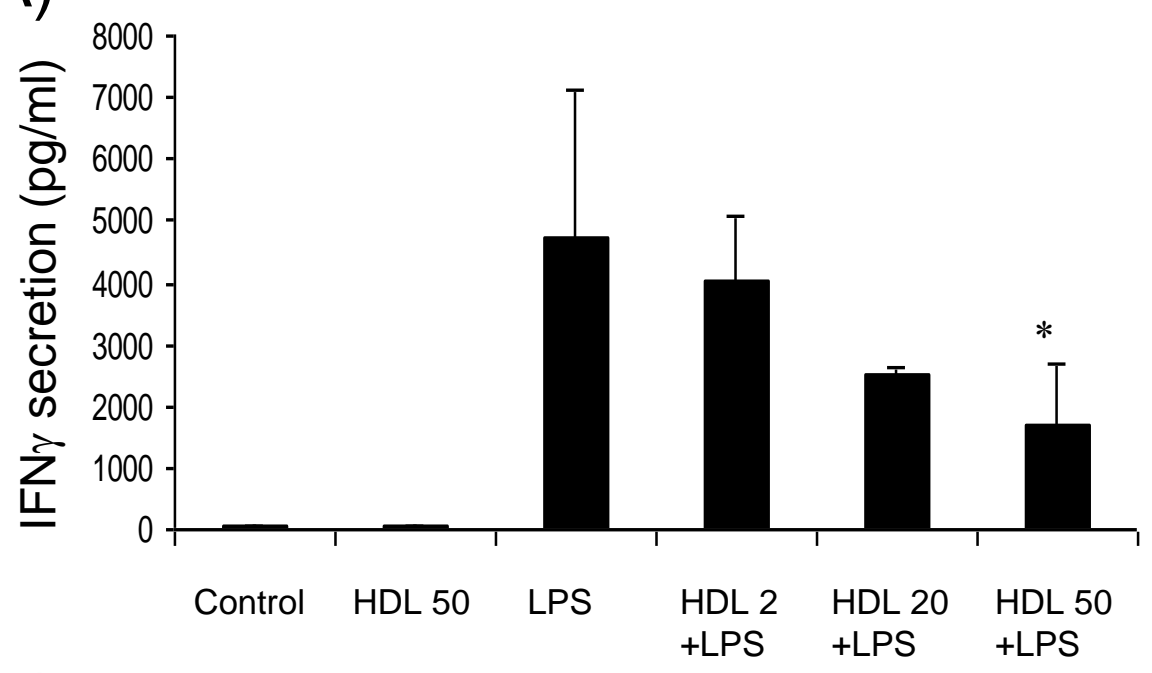

(B)
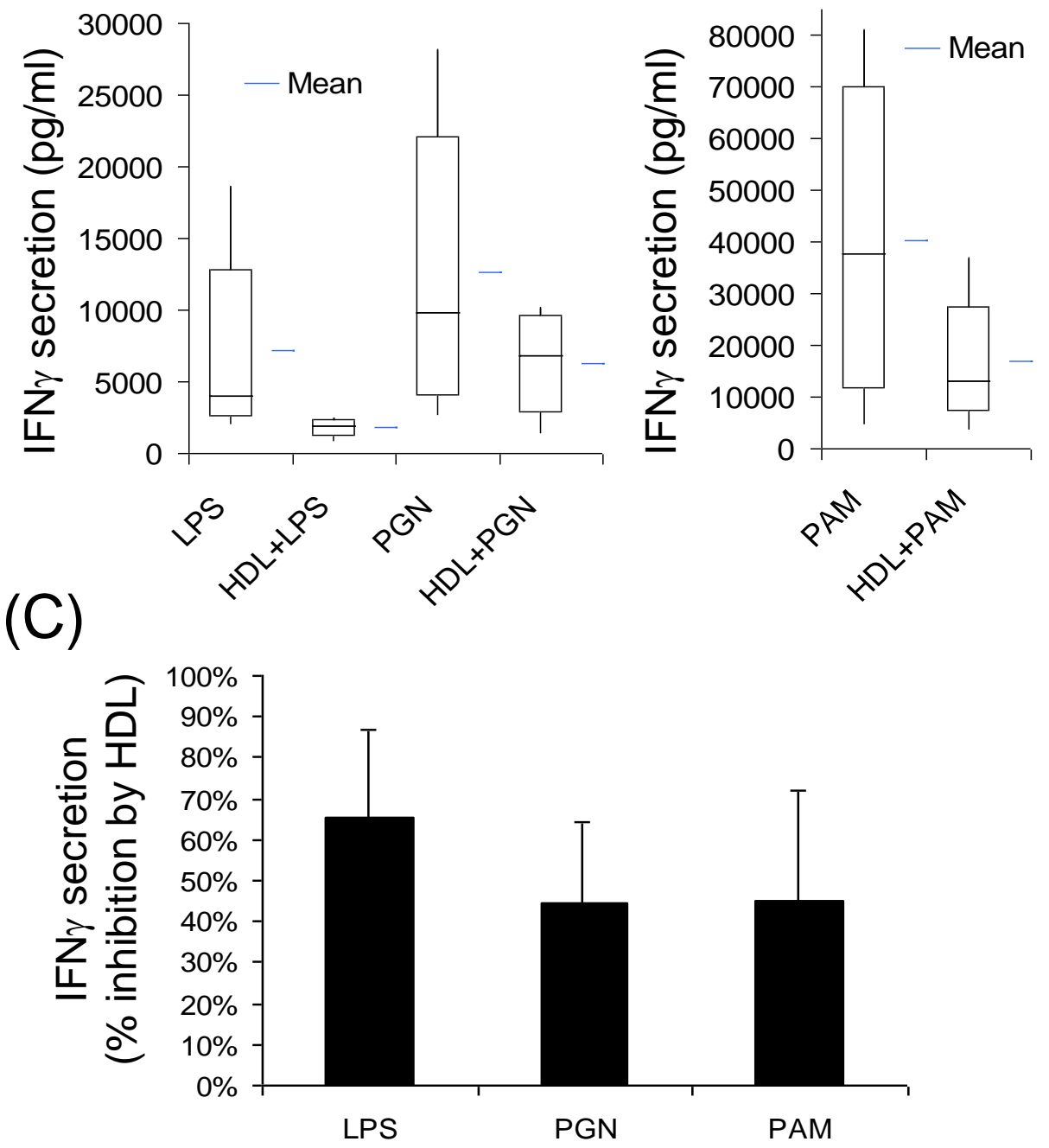

Figure 2 
(A)

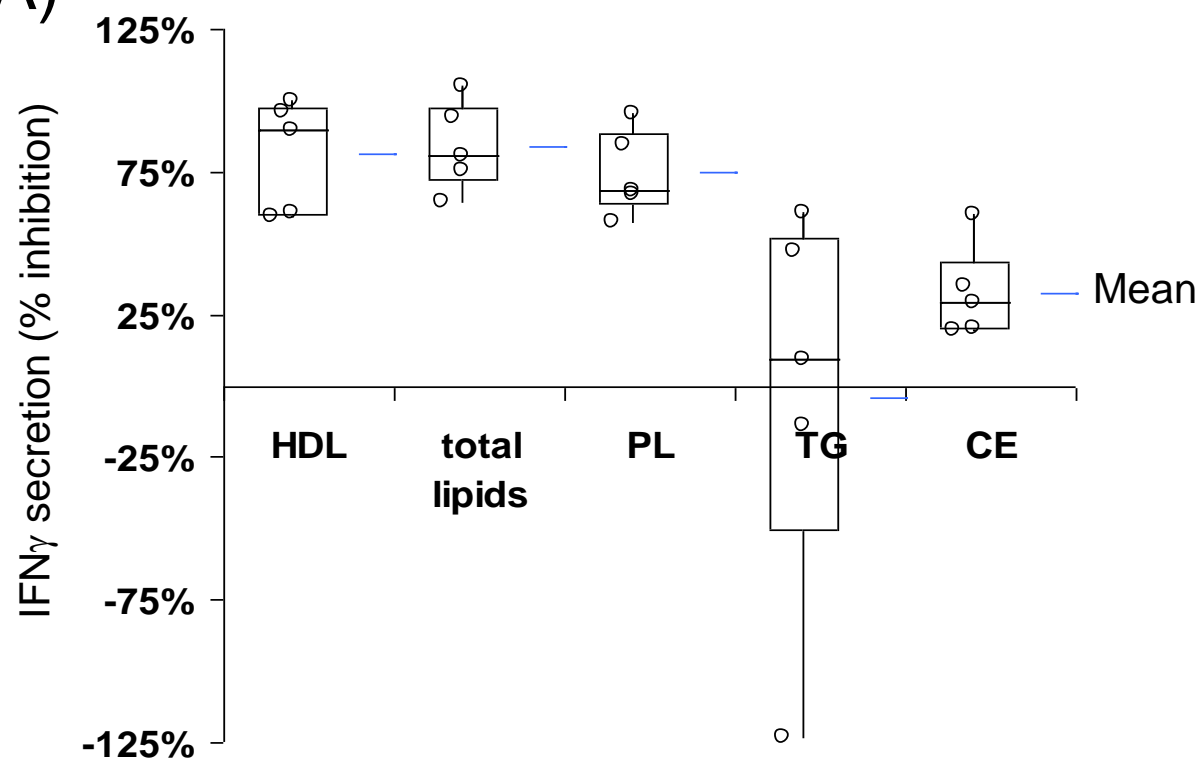

(B)

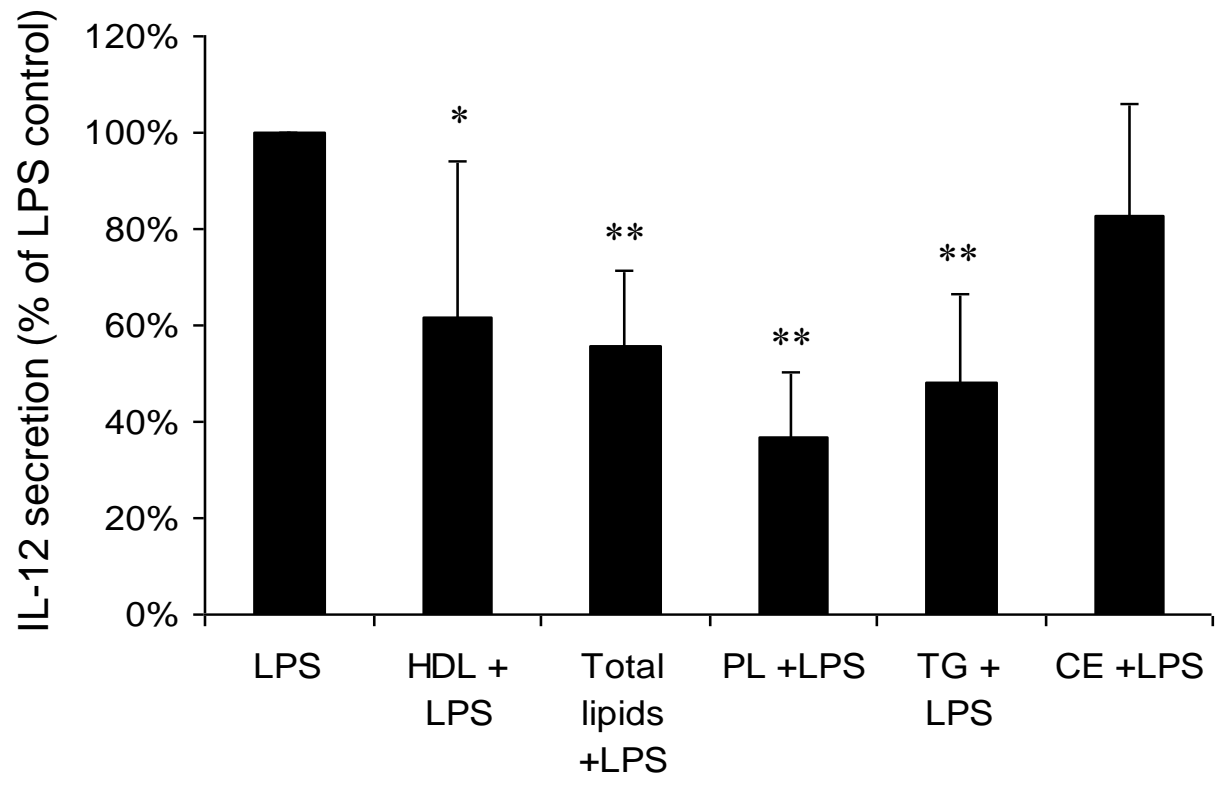

Figure 3 
(A)

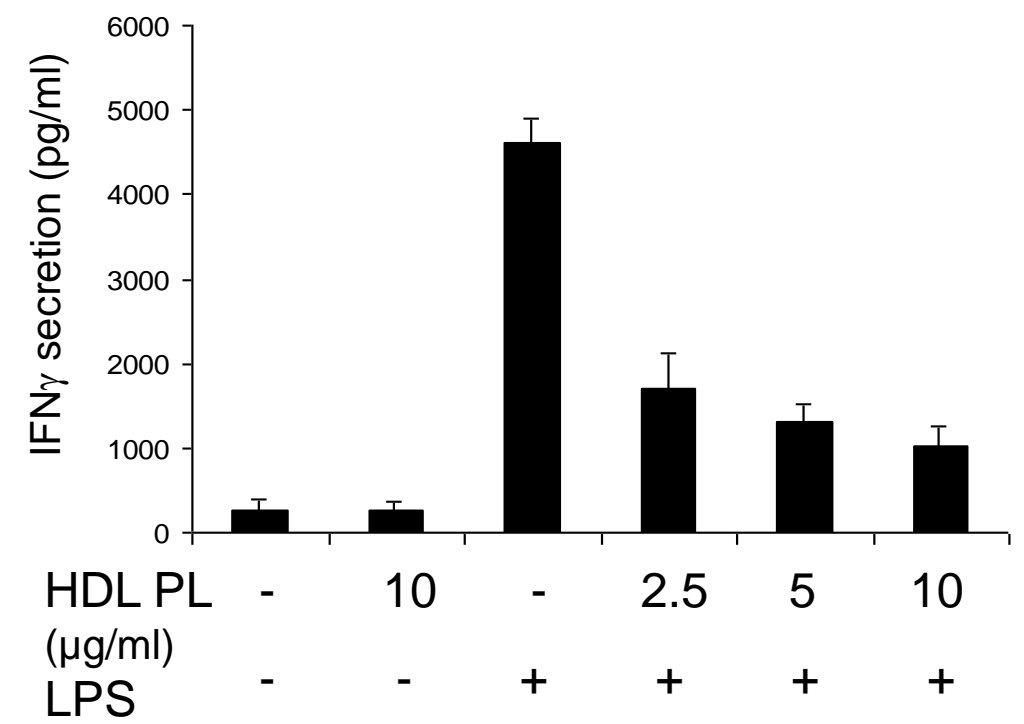

(C)

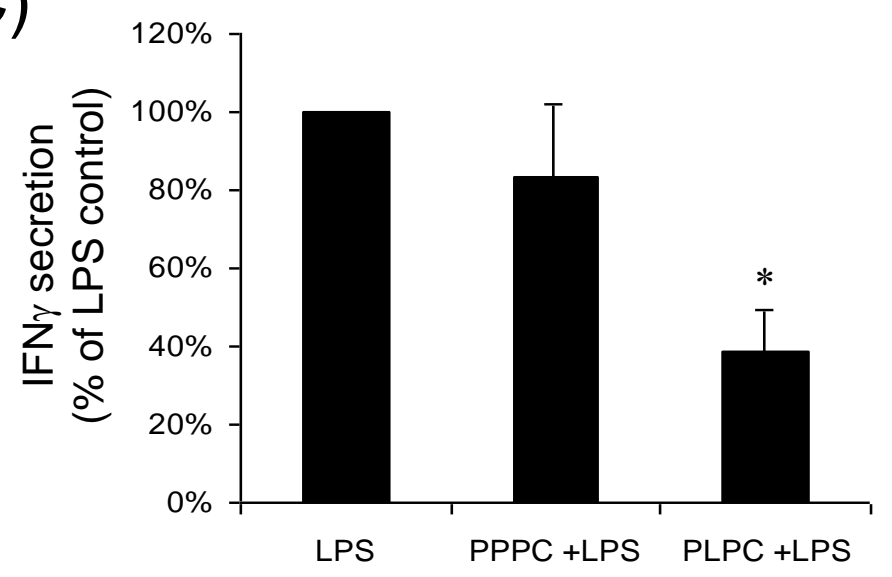

(B)

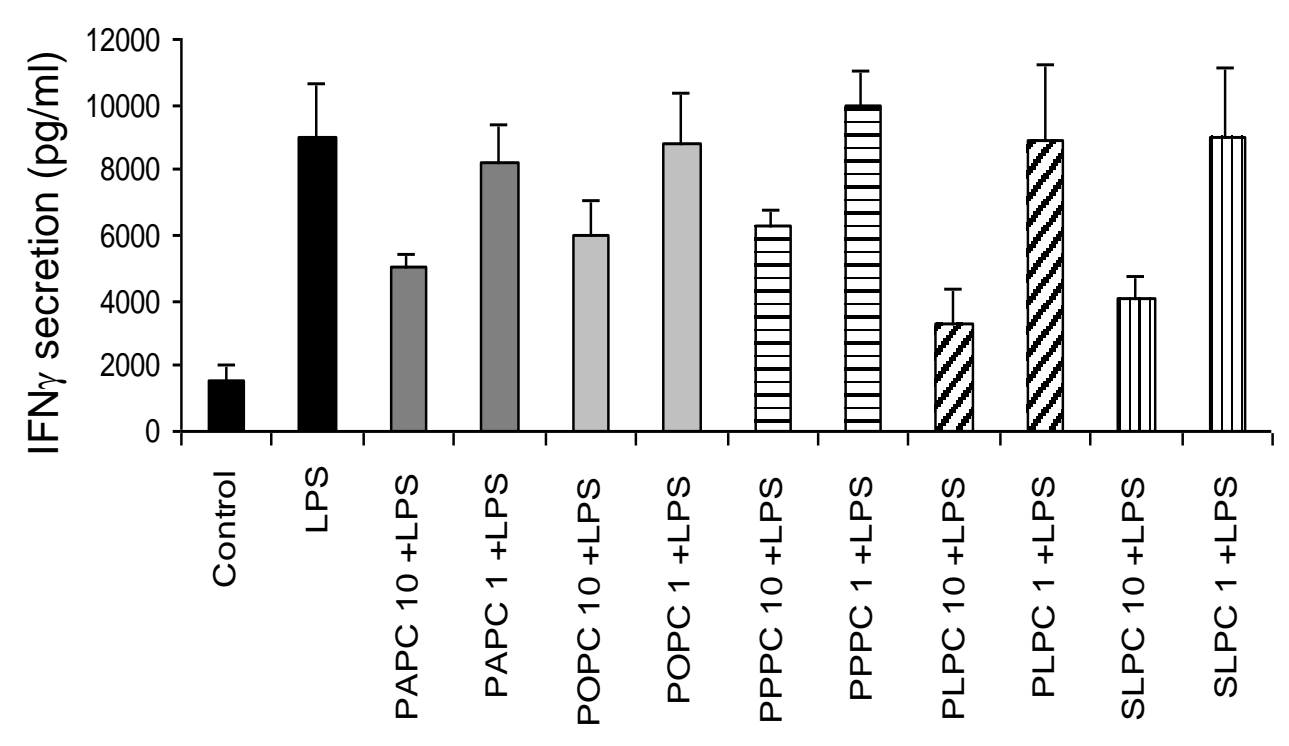

(D)

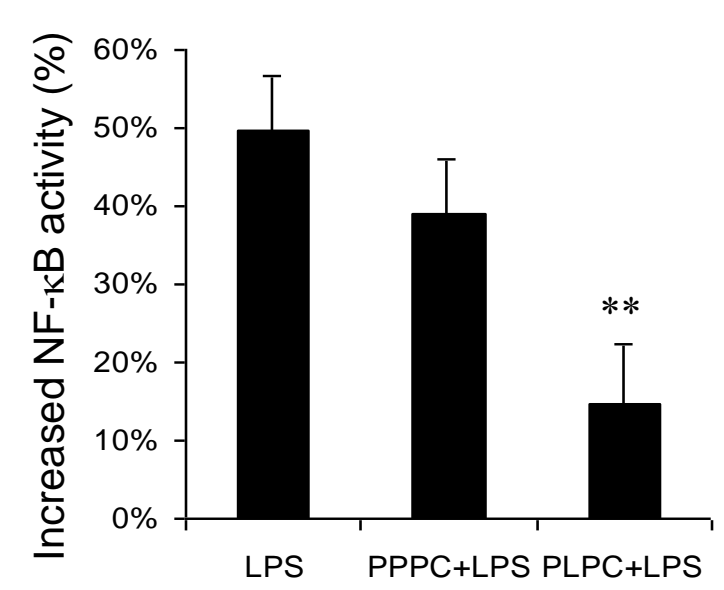

Figure 4 


\section{SUPPLEMENTARY METHODS}

\section{Cytokine assay}

Cytokines concentrations were determined using sandwich ELISA specific for IL-12 p40 (Invitrogen, Cergy Pontoise, France), IL-6, TNFa, IL-10 (Endogen, Woburn, MA, USA) or using Cytometric Bead Array flex sets (BD biosciences, Franklin Lakes, NJ, USA) for IL-8 and IFN $\gamma$.

\section{Fatty acids content in total lipid extracts from lipoproteins}

Total lipid extracts were obtained by the Folch extraction procedure as explained in the Methods section. Fatty acid composition of these extracts was determined by gas chromatography. Briefly, an aliquot of total lipid extract was dried under nitrogen before transmethylation by addition of 1 volume of $5 \% \mathrm{H}_{2} \mathrm{SO}_{4}$ in methanol. Transmethylation was carried out at $100^{\circ} \mathrm{C}$ for 90 min in screw-capped tubes. The reaction was terminated by the addition of 1.5 volume of ice-cold $5 \%(\mathrm{w} / \mathrm{v}) \mathrm{K}_{2} \mathrm{CO}_{3}$, and the fatty acid methyl esters were extracted with isooctane and analysed using a PerkinElmer Life Sciences chromatograph model 5830, equipped with a capillary column $(30 \mathrm{~m} \times 0.32 \mathrm{~mm}$, Supelco (Sigma, St Quentin Fallavier, France) and a flame ionization detection. The column was two-step programmed from 135 to $160^{\circ} \mathrm{C}$ at $2^{\circ} \mathrm{C} / \mathrm{min}$ and from 160 to $205^{\circ} \mathrm{C}$ at $1.5^{\circ} \mathrm{C} / \mathrm{min}$; the detection temperature was maintained at $250^{\circ} \mathrm{C}$. The vector gas was helium at a pressure of 0.8 pounds/square inch (5520 Pa). Peaks were identified using standard fatty acid methyl esters.

\section{EMSA}

$4 \times 10^{6}$ monocytes were differentiated into DCs as described in material and methods and treated at day 4 with $10 \mu \mathrm{g} / \mathrm{ml}$ PLPC, 12,5 $\mu \mathrm{g} / \mathrm{ml}$ 9-HODE (Cayman Chemicals, Ann Arbor, 
MI, USA), $40 \mu \mathrm{M}$ lysophosphatidylcholine (LPC) or equal volumes of ethanol for control cells. Cells were then incubated at $37^{\circ} \mathrm{C}$ for $4 \mathrm{~h}$ or $1 \mathrm{~h}$. After treatment, the cells were washed twice with PBS, resuspended in $400 \mu$ l of ice-cold hypotonic buffer (10 mM HEPES (pH 7.9), $10 \mathrm{mM} \mathrm{KCl}, 0.01 \mathrm{M} \mathrm{DTT}, 1.5 \mathrm{mM} \mathrm{MgCl}_{2}$, and 1 x protease inhibitor cocktail (Sigma)) for 10 min, vortexed and centrifuged at $15000 \mathrm{x}$ g for $30 \mathrm{~s}$ at $4^{\circ} \mathrm{C}$. Nuclei were lysed in $40 \mu \mathrm{l}$ icecold saline buffer (20 mM HEPES (pH 7.9), $420 \mathrm{mM} \mathrm{NaCl}, 0.2 \mathrm{mM}$ EDTA, $1.5 \mathrm{mM} \mathrm{MgCl}{ }_{2}$, $25 \%$ glycerol, and $1 \mathrm{x}$ protease inhibitor mixture (Sigma)), at $4{ }^{\circ} \mathrm{C}$ for $20 \mathrm{~min}$, vortexed and centrifuged at $15000 \mathrm{x}$ g for $5 \mathrm{~min}$ at $4^{\circ} \mathrm{C}$. Protein concentrations were determined by Micro BCA Protein Assay Reagent (Pierce, Rockford, IL, USA). The sequence of the doublestranded oligonucleotide for detection of PPAR binding was: 5'GGgGtCAGtaAgtCAGAGGCCAGGGA-3', according to Tontonoz et al '. Oligonucleotide was end-labeled with $\left[\gamma_{-}{ }^{32} \mathrm{P}\right] \mathrm{ATP}$ (Perkin Elmer, Waltham, MA, USA) by T4 polynucleotide kinase (New England Biolab, Beverly, MA). Nuclear extracts ( $1 \mu \mathrm{g})$ were then mixed with $2 \mu \mathrm{g}$ of poly (dI-dC) in a $20 \mu$ l reaction containing $10 \mathrm{mM}$ Tris, $\mathrm{pH} 7.5$ / $50 \mathrm{mM}$ $\mathrm{NaCl} / 1$ mM DTT / 1 mM EDTA / $10 \%$ glycerol and ${ }^{32}$ P-labeled oligonucleotide. After a 20 min incubation at room temperature, DNA-protein complexes were resolved on a $4 \%$ polyacrylamide native gel in a $0.5 \mathrm{x}$ Tris-Glycine EDTA buffer. Radioactive bands were visualized using a Typhoon PhosphorImager.

1 Tontonoz P, Nagy L, Alvarez JG, Thomazy VA, Evans RM. PPARgamma promotes monocyte/macrophage differentiation and uptake of oxidized LDL. Cell 1998; 93: 241-52. 


\section{Supplementary Fig. 1.}

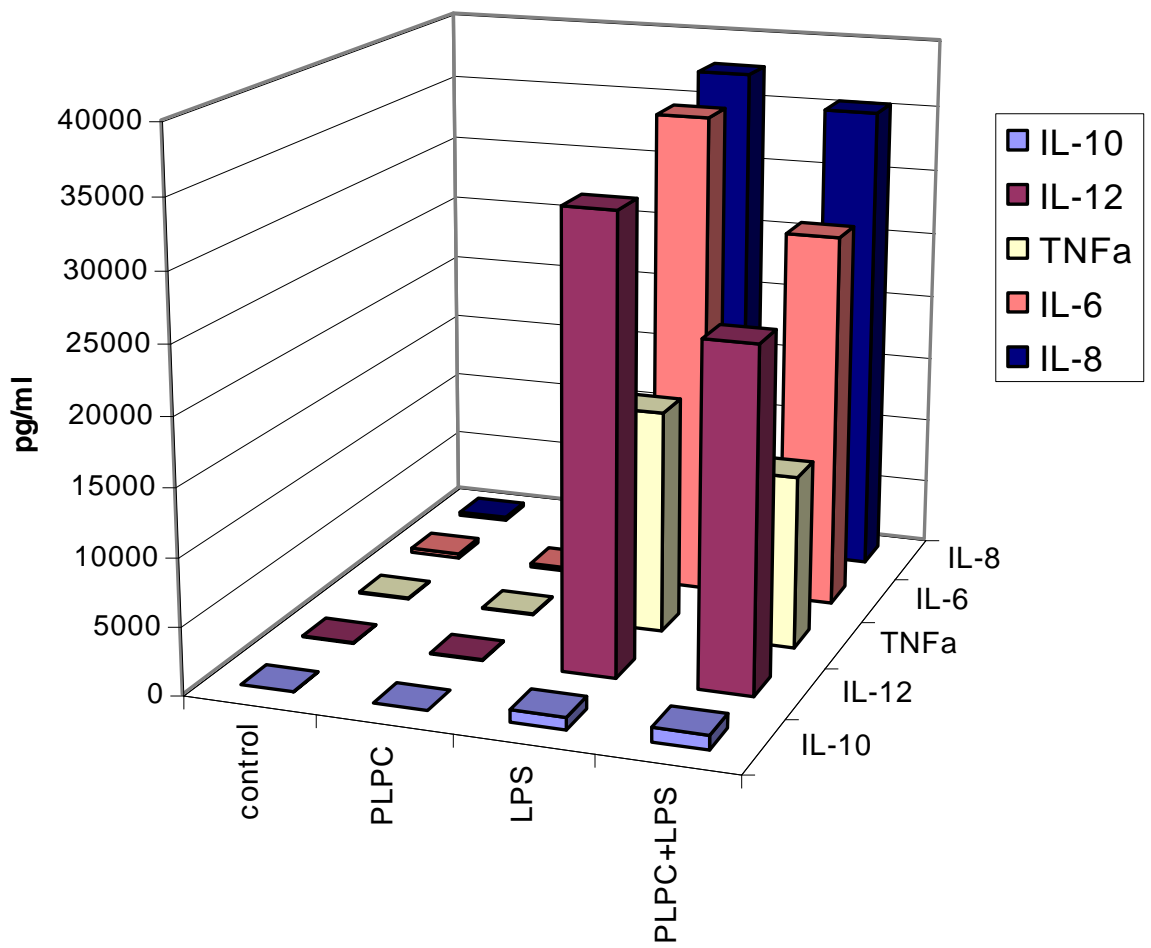

Cytokine secretion profile of PLPC-treated DCs. DCs were differentiated from blood monocytes, treated by PLPC at day 4 and maturation was induced at day 5 by LPS addition. Cytokine secretions were assayed in DC supernatants collected at day 6 at the end of the maturation process. The mean secretion of IL-6, IL-8, IL-10, TNF $\alpha$ and IL-12p40 for 7 independent experiments is shown. 


\section{Supplementary Fig. 2.}

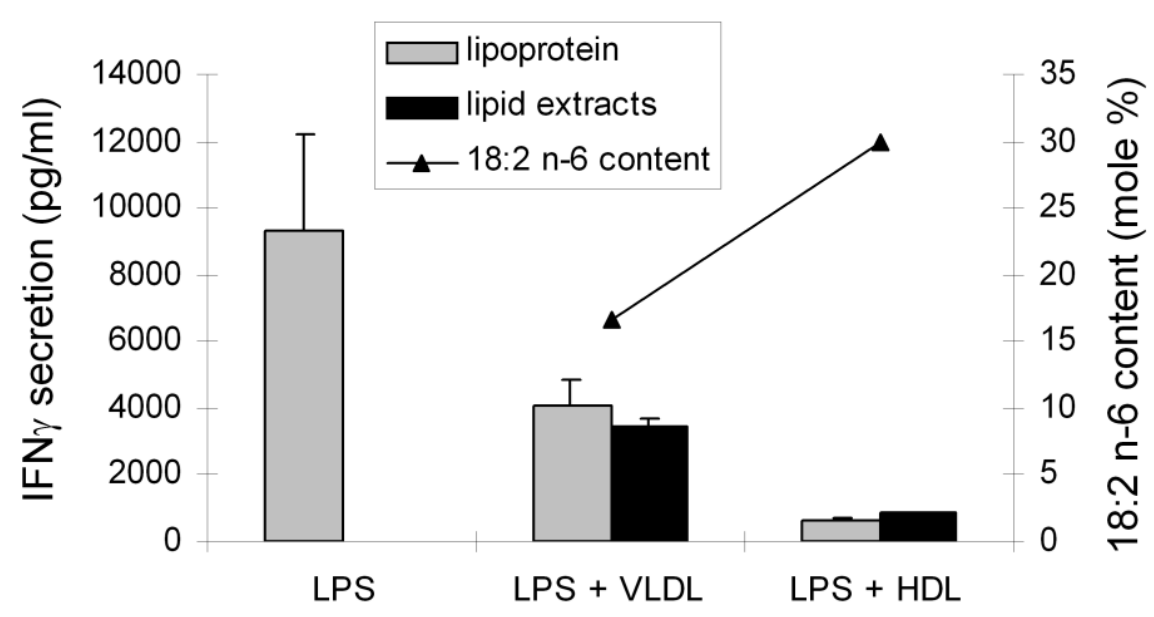

Lipoprotein content in linoleic (18:2 n-6) fatty acid and inhibition of the Th1 function of mature DC. VLDL and HDL were isolated from human plasma and added at day 4 on DC at $50 \mu \mathrm{g} / \mathrm{ml}$ of phospholipids. At day 5, maturation was stimulated by LPS. DC harvested at day 6 were cocultured in triplicates for 5 days with allogeneic T cells (MLR) at a 1/10 DC/T cells ratio. IFN $\gamma$ was assayed in coculture supernatant.

The fatty acid content of VLDL and HDL was determined after extraction of total lipids by the Folch procedure. After transmethylation, fatty acids were analysed by gas-phase chromatography and expressed as mole $\%$ of total fatty acids content. 


\section{Supplementary Fig. 3.}

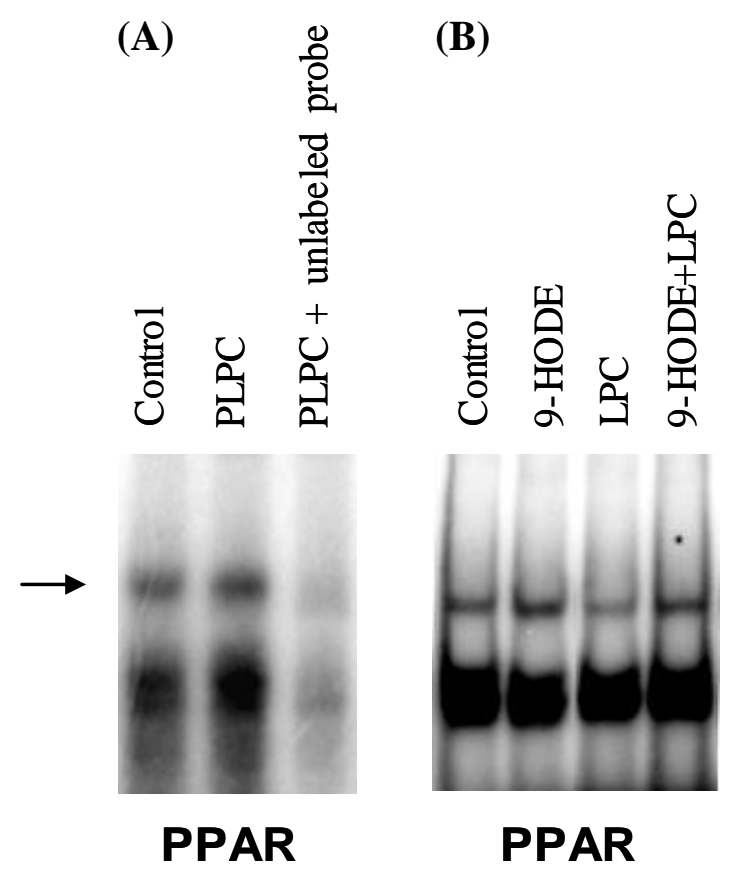

PLPC treatment of DC enhances PPAR $\gamma$ activation. DC were treated at day 4 by $10 \mu \mathrm{g} / \mathrm{ml}$ PLPC for $4 \mathrm{~h}$ (A) or by $12,5 \mu \mathrm{g} / \mathrm{ml}$ 9-HODE with or without $40 \mu \mathrm{M}$ LPC (B). The cells were then washed and lysed. Nuclear extracts were prepared from harvested cells and the binding activity of PPAR $\gamma$ was measured by EMSA using a ${ }^{32} \mathrm{P}$-labeled specific probe. The arrow indicates the PPAR $\gamma$ specific band. 